\title{
Some neurophysiological constraints on models of word naming
}

\author{
J.R. Binder*, D.A. Medler, R. Desai, L.L. Conant, and E. Liebenthal \\ Department of Neurology, Medical College of Wisconsin, Language Imaging Laboratory, 9200 W. Wisconsin Avenue, Milwaukee, WI 53226, USA
}

Received 23 December 2004; revised 24 March 2005; accepted 15 April 2005

Available online 25 May 2005

\begin{abstract}
The pronunciation of irregular words in deep orthographies like English cannot be specified by simple rules. On the other hand, the fact that novel letter strings can be pronounced seems to imply the existence of such rules. These facts motivate dual-route models of word naming, which postulate separate lexical (whole-word) and non-lexical (rulebased) mechanisms for accessing phonology. We used fMRI during oral naming of irregular words, regular words, and nonwords, to test this theory against a competing single-mechanism account known as the triangle model, which proposes that all words are handled by a single system containing distributed orthographic, phonological, and semantic codes rather than word codes. Two versions of the dual-route model were distinguished: an 'exclusive' version in which activation of one processing route predominates over the other, and a 'parallel' version in which both routes are equally activated by all words. The fMRI results provide no support for the exclusive dual-route model. Several frontal, insular, anterior cingulate, and parietal regions showed responses that increased with naming difficulty (nonword $>$ irregular word $>$ regular word) and were correlated with response time, but there was no activation consistent with the predicted response of a nonlexical, rule-based mechanism (i.e., nonword > regular word $>$ irregular word). Several regions, including the angular gyrus and dorsal prefrontal cortex bilaterally, left ventromedial temporal lobe, and posterior cingulate gyrus, were activated more by words than nonwords, but these 'lexical route' regions were equally active for irregular and regular words. The results are compatible with both the parallel dual-route model and the triangle model. 'Lexical route' regions also showed effects of word imageability. Together with previous imaging studies using semantic task contrasts, the imageability effects are consistent with semantic processing in these brain regions, suggesting that word naming is partly semantically-mediated. (c) 2005 Elsevier Inc. All rights reserved.
\end{abstract}

Keywords: Word naming; Dual-route model; Triangle model

\section{Introduction}

The correspondence between spoken and written forms of a language is not always systematic. While in some alphabetic

\footnotetext{
* Corresponding author.

E-mail address: jbinder@mcw.edu (J.R. Binder).

Available online on ScienceDirect (www.sciencedirect.com).
}

orthographies the sound of a word can be worked out using rules of pronunciation, in most, there are varying degrees of irregularity in the mapping between print and sound. In English, for example, Bernard Shaw pointed out that the word "fish" could be written ghoti if one were mischievous enough to borrow the spelling for /f/ from rough, the spelling of /I/ from women, and the spelling of /sh/ from nation. Words like colonel and yacht are only some of the more extreme examples of such irregularity of pronunciation, which is pervasive in English and is seen in many of its more common words, including some, many, of, the, and word just used in this sentence.

While the pronunciation of these 'irregular' words would seem to be learned through rote memorization of the whole word, there is also a degree of correspondence between letters and sounds in English that presumably assists with pronunciation. In the case of novel letter strings like mave, such correspondences seem necessary to construct a reasonable pronunciation without any prior example. This apparent qualitative distinction between whole-word and rule-based pronunciation forms the conceptual basis for dual-route models of word naming. The essential features of these models include a distinct lexical pathway for pronunciation of irregular words, which in some versions includes activation of semantic representations for the word; and a nonlexical, rule-based pathway for constructing the pronunciation of novel and unfamiliar words, often referred to as the graphemephoneme conversion (GPC) system. Regularly spelled words can be handled by either route, with word frequency being the major determinant of which pathway is selected. These models have a long and venerable history (Coltheart et al., 1977; Marshall and Newcombe, 1973; Meyer et al., 1974; Morton and Patterson, 1980), continue to be updated and expanded (Coltheart et al., 1993, 2001), and continue to garner empirical support (Andrews and Scarratt, 1998; Baayen and Schreuder, 1999; Jobard et al., 2003; Joubert and Lecours, 2000; McKague et al., 2001; Simos et al., 2000; Visser and Besner, 2001).

Alternatives to dual-route theory postulate a single mechanism that generates pronunciations for all words. The most prominent single-mechanism accounts are neural network models in which word pronunciations are learned through repeated training with a corpus of written and spoken inputs. After a set of optimal connection weights has been learned, both irregular words and 
nonwords are pronounced using the same network. The first version of this model used a single pathway mapping orthography directly to phonology (Seidenberg and McClelland, 1989), but subsequent elaborations have added a layer of semantic units not only to assist with pronunciation of irregular words but also to more accurately account for dissociations between nonword and irregular word performance observed in patients with acquired dyslexia (Harm and Seidenberg, 2004; Plaut and Shallice, 1993; Plaut et al., 1996). This version has become known as the 'triangle model' in reference to the triangular architecture linking orthographic, phonological, and semantic units. While the addition of a semantic pathway would seem at first to blur the distinction between the dual-route and single-mechanism accounts, there remains one critical difference between the models. Whereas the dual-route theory postulates two qualitatively different mechanisms for generating phonology (whole-word retrieval vs. rule-based construction), the triangle model possesses only one mechanism, involving interactive parallel processing by sublexical orthographic, phonological, and semantic units. Consequently, the triangle model makes no reference to a lexicon of word form representations in the brain.

Several notable attempts have been made to test the dual-route model with functional neuroimaging, yet results have been far from consistent (Jobard et al., 2003; Mechelli et al., 2003). One relatively reliable finding is stronger activation to nonwords than words in the left frontal operculum and adjacent anterior insula (Fiez et al., 1999; Hagoort et al., 1999; Herbster et al., 1997; Mechelli et al., 2003; Paulesu et al., 2000; Xu et al., 2001). Because the dual-route model proposes greater reliance on the nonlexical GPC system in the case of nonwords, these findings have often been interpreted as evidence for such a system in the left inferior frontal lobe. This region has also shown stronger activation to irregular words compared to regular words, however, suggesting a closer relationship to naming difficulty than to the type of pathway engaged (Fiez et al., 1999; Herbster et al., 1997). Both nonwords and irregular words are named more slowly and less accurately than regular words (Balota et al., 2004; Carr and Pollatsek, 1985; Seidenberg et al., 1984). These facts present an inherent problem for any attempt to compare these classes of stimuli using functional imaging techniques, which are highly sensitive to task difficulty (Adler et al., 2001; Braver et al., 1997, 2001; Honey et al., 2000; Jonides et al., 1997; Ullsperger and von Cramon, 2001). The problem is that changes in task difficulty can alter demands on general and selective attention, working memory, response monitoring, decision making, and other executive processes, regardless of the type of stimulus being processed. Such effects do not constitute evidence for differential activation of one processing pathway over another.

In assessing the evidence from functional imaging, it is useful to be as explicit as possible concerning the predictions made by each model (Fig. 1). We distinguish between two rather different interpretations of dual-route theory, called here the 'exclusive' and the 'parallel' models. The exclusive model refers to earlier forms of dual-route theory based on a highly modular conception of the model's processing components, such as the orthographic and phonological lexicons, the GPC system, and so on. This version of the theory (Fig. 1, top row) has often been interpreted as postulating two exclusive pathways, only one of which is selected for processing a given item. Presentation of a nonword is assumed to engage the rule-based GPC route alone, whereas presentation of an irregular word engages the lexical route alone or to a much greater degree than the GPC route. Thus, this form of dual-route theory has often been interpreted as predicting mutually distinct areas of activation for nonwords and irregular words (Jobard et al., 2003; Rumsey et al., 1997; Simos et al., 2000). Regular words (especially low-frequency regular words) are expected to produce more activation of the GPC route than irregular words. Irregular words should produce more activation of the lexical pathway than regular words, since some regular words are processed by the GPC route rather than by the lexical route.

More recent, computational forms of the dual-route model, however, make somewhat different predictions. In the best-known such version (Coltheart et al., 1993, 2001), irregular (and regular) words are always processed in parallel by both the lexical and GPC routes (Fig. 1, middle row). Since words always activate the GPC system, this form of the model does not necessarily predict any areas with greater activation for nonwords than words. Like the exclusive model, the parallel model predicts greater activation of the lexical pathway for words (both regular and irregular) compared to nonwords, since nonwords cannot activate word units in the orthographic and phonological lexicons that comprise this pathway. In contrast to the exclusive version, however, the parallel dual-route model assumes that both regular and irregular words are always processed by the lexical pathway, so there should be no effect of spelling-sound regularity on activation of the lexical pathway.

Distinct areas of activation by words relative to nonwords are also predicted, however, by the single-mechanism triangle model, because words have meaning and therefore activate semantic representations to a greater degree than nonwords (Fig. 1, bottom row). Like the parallel dual-route model, the triangle model assumes that all words are processed by the entire system, so there should be no difference in activation patterns for regular and irregular words. Also, like the parallel dual-route model, the triangle model predicts little, if any, activation favoring nonwords over words, since all stimuli activate the orthographic and phonological units.

Thus, the parallel dual-route and triangle models make very similar predictions about the effects of lexicality and regularity of pronunciation on brain activity. The principal difference between these models lies in whether the pronunciation of words is facilitated by word codes (the orthographic and phonological lexicons) or by semantic codes. According to the dual-route account, activation by words relative to nonwords represents processing of word codes and should not be modulated by semantic variables. In the triangle model, on the other hand, these areas process semantic codes and might therefore be sensitive to concreteness/imageability, taxonomic category, prototypicality, level of specificity, and other semantic factors. To the extent that lexical and semantic systems are spatially distinct in the cortex, the two models might also predict different specific areas of activation in a contrast between words and nonwords. For example, semantic memory systems have often been localized to ventral areas in the temporal lobe and to the angular gyrus (Binder and Price, 2001; Damasio et al., 2004; Gainotti, 2000; Martin, 2001), whereas some studies suggest representation of lexical codes in more dorsolateral temporal regions (Howard et al., 1992; Perani et al., 1996; Price et al., 1996; Small et al., 1996). To date, however, few studies have shown any activation for words over nonwords during simple pronunciation tasks, making adjudication of this matter difficult.

In the following fMRI study, we attempted to provide clearer evidence on these predictions in four ways. First, a relatively large 


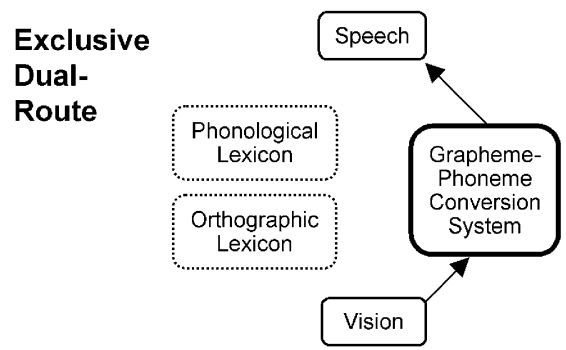

Nonword

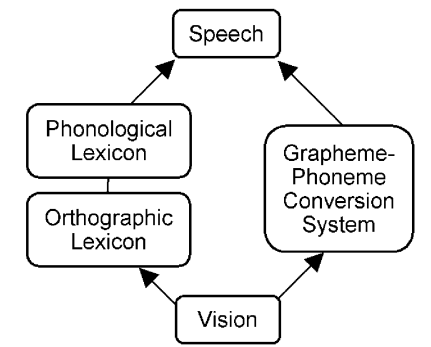

Regular Word

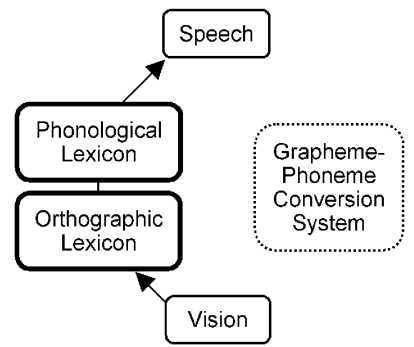

Irregular Word

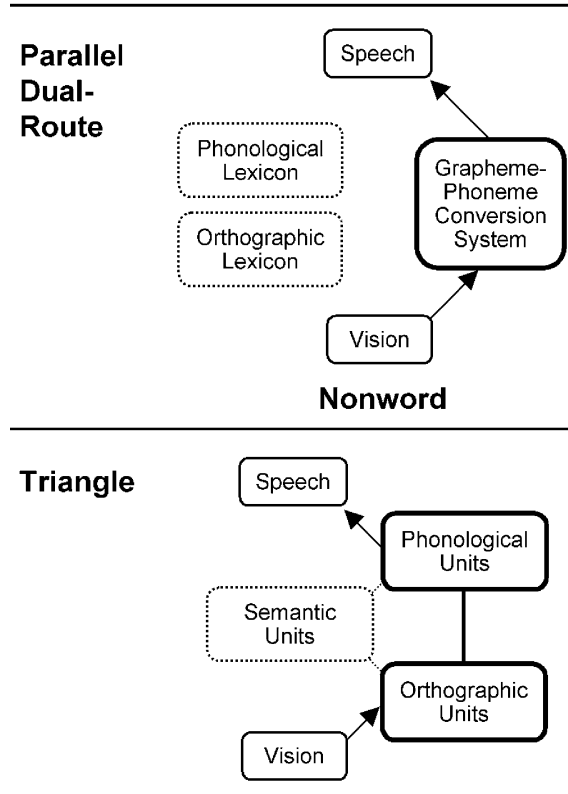

Nonword

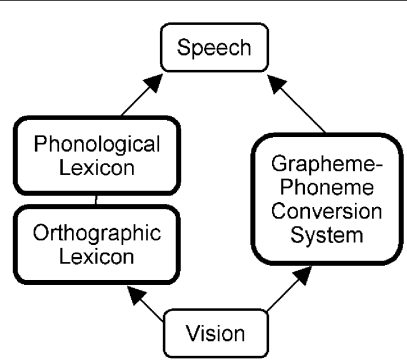

Regular Word

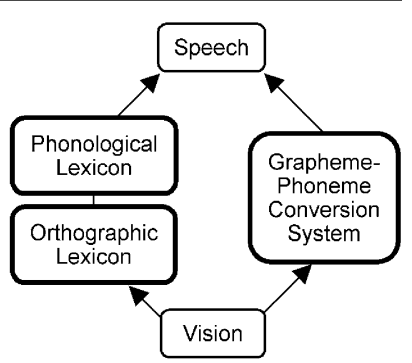

Irregular Word

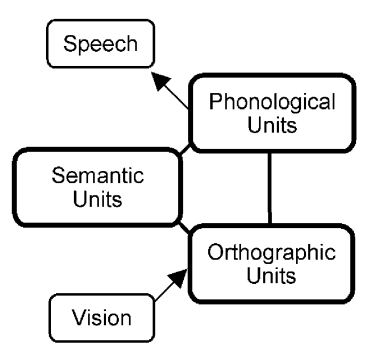

Regular Word

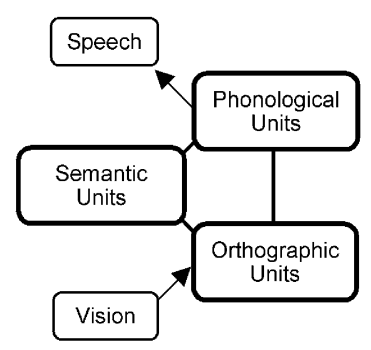

Irregular Word

Fig. 1. Schematic representations of three models of word naming and associated patterns of activation by nonwords, regular words, and irregular words. Thickness of the line around each processing component represents the relative degree of activation.

sample of participants was studied to ensure reliable activation patterns and to optimize detection of subtle differences between conditions. Second, an overt naming task was used to ensure that accurate phonological representations were fully accessed. This method also provided vocal response times (RT) for use in assessing differences in task difficulty. These RT data were incorporated directly into the image analysis in an attempt to delineate brain areas modulated by task difficulty. Third, we used carefully matched nonword, regular word, and irregular word stimulus sets to avoid potential confounding from stimulus length, visual familiarity, word frequency, and imageability, all of which are known to influence word reading. Finally, because of the differential role played by semantic processes in the models, and because of recent results showing large effects of word imageability on brain activation (Binder et al., in press), we manipulated this variable to identify brain regions specifically involved in processing semantic information.

Several complexities arise in attempting to distinguish general effects of task difficulty from domain-specific word naming processes. It is helpful to recognize that differences in task difficulty are an inherent confound in comparisons among regular words, irregular words, and nonwords, because variation in task difficulty is inevitably correlated to some degree with other differences between these conditions. At the same time, variation in task difficulty also occurs within each condition, and these effects of task difficulty can be isolated from the condition effects of interest. We accomplished this by using multiple regression analyses in which normalized RT values were coded separately for each stimulus condition. Because these regressors are orthogonal to the condition regressors, they account for variance due to RT that is independent from variance due to the stimulus conditions. This analysis thus identified candidate brain regions that are likely to be modulated by non-specific differences in task difficulty, such as working memory, attention, decision, and response selection systems. These results are informative because the brain areas so modulated can be compared directly to those showing condition effects. Condition effects (i.e., differences between nonwords, regular words, and irregular words) appearing in brain regions that are modulated by general task difficulty are likely to reflect non-specific differences in task difficulty between conditions. In contrast, brain regions involved in more specific word naming processes should not be modulated by within-condition variance in RT.

\section{Methods}

\section{Participants}

Participants were 24 healthy, literate adults (12 men), aged 18 48 years $($ mean $=27.5)$, with no history of neurological disease or 
learning disability. Years of education ranged from 11 to 24 (mean = 16). All were right-handed on the Edinburgh Handedness Inventory (Oldfield, 1971) and spoke English as a first language. All participants provided written informed consent in accordance with the institutional review board and were paid an hourly stipend.

\section{Stimuli and task}

The 240 reading stimuli included 160 English words and 80 word-like nonwords, all ranging from 4 to 6 characters in length (Table 1). Words were all nouns and of low-to-medium word frequency (range $0-65 /$ million). There were 80 Irregular and 80 Regular words. Irregular words were mostly taken from previous studies of word naming (Coltheart et al., 1979; Seidenberg et al., 1984; Taraban and McClelland, 1987; Waters and Seidenberg, 1985). These items included both spellings that violate common pronunciation patterns ('exception' words such as wand, sweat, plaid, caste, spook, threat) and unique spellings that violate pronunciation rules ('strange' words such as aisle, choir, fruit, heir, corps, scheme). Regular words had regular spelling-to-sound mappings (e.g., lice, hedge, sleeve, deed, pride, grudge). Equal numbers of concrete and abstract nouns were included in each set.

Irregular and Regular word sets were matched on letter and phoneme length, mean positional bigram frequency, orthographic neighborhood count, and word frequency using phonological data and frequency counts from the CELEX lexical database (Baayen et al., 1995). The sets were also matched on imageability. Imageability ratings were taken from the MRC lexical database (Wilson, 1988) (www.psy.uwa.edu.au/mrcdatabasewa_mrc.htm) and from norms published by Bird et al. (2001) and Cortese and Fugett (2004). Imageability ratings for the study items ranged from 140 to $659($ mean $=458, \mathrm{SD}=125)$ and were uncorrelated with letter length, phoneme length, mean positional bigram frequency, orthographic neighborhood count, or word frequency.

The 80 Nonwords were generated by Markov chaining based on position-specific bigram frequencies from the CELEX database. These were selected from a larger pool of stimuli to create a set of easily pronounceable nonwords matched to the word sets on the four lexical characteristics listed in Table 1. ANOVAs $(d f=2237)$ showed no significant differences across the three conditions on any of these variables (all $P>0.1$ ).

In addition to the word and nonword conditions, 80 trials using false-font stimuli were included as a control for low-level sensory processes. Results from this condition are not relevant to the aims of this study and will not be discussed here. Finally, 80 trials of fixation only (no stimulus except a fixation cross) were included as a low-level baseline.

Participants were asked to read each word or nonword aloud "as quickly as possible without making errors". Participants

Table 1

Summary statistics (mean and SD) for the five reading conditions

\begin{tabular}{lllllll}
\hline Condition & Letters & Phonemes & MPBF & ON & WFreq & Img \\
\hline Irregular & $4.9(0.7)$ & $3.4(0.8)$ & $1280(839)$ & $3.8(3.7)$ & $12(13)$ & $450(130)$ \\
Regular & $4.8(0.7)$ & $3.5(0.6)$ & $1228(787)$ & $5.0(4.1)$ & $10(13)$ & $466(121)$ \\
Nonword & $4.9(0.7)$ & $3.5(0.6)$ & $1266(876)$ & $4.3(4.2)$ & - & - \\
\hline
\end{tabular}

$\mathrm{MPBF}=$ mean positional bigram frequency; $\mathrm{ON}=$ orthographic neighborhood size; WFreq = word frequency; Img = imageability rating. MPBF and WFreq reflect counts per million words. practiced the tasks prior to entering the scanner, using items not included in the experiment, and were trained to respond within a time window of about $4 \mathrm{~s}$ after stimulus onset. This was accomplished by using an auditory warning cue, consisting of two short tones, presented $3750 \mathrm{~ms}$ after the onset of each stimulus to signal the end of the response window. Stimuli were computer generated using Psyscope software (Cohen et al., 1993), which also recorded vocal RT. Responses were monitored and phonetically transcribed on-line by an experimenter and later scored for accuracy. A liquid crystal display projector was used to rearproject the stimuli onto a screen located near the participant's feet. Subjects viewed the stimuli through prism lenses. Stimuli were presented in white lower-case Geneva font on a black background and subtended an average horizontal visual angle of about $3.5^{\circ}$ at the center of the field of view. Order of presentation was randomized. Trials occurred every $7 \mathrm{~s}$ and were synchronized with image acquisitions, as described below. Stimulus duration was 2 s. A fixation cross appeared during each interstimulus interval. As in the practice session, an auditory warning tone signaled the end of the response window after each trial.

\section{MRI acquisition}

MRI data were acquired on a GE Signa 1.5-T scanner (GE Medical Systems, Milwaukee, WI) using a 3-axis, local gradient coil with a built-in transmit-receive RF coil (Medical Advances, Inc., Milwaukee, WI). High-resolution, T1-weighted anatomical reference images were acquired as a set of 124 contiguous sagittal slices $(0.9375 \times 0.9375 \times 1.2 \mathrm{~mm})$ using a spoiled-gradient-echo sequence ("SPGR", GE Medical Systems, Milwaukee, WI). Functional imaging used a clustered (or 'sparse') acquisition, gradient-echo, echoplanar sequence with the following parameters: $40 \mathrm{~ms}$ echo time, $7 \mathrm{~s}$ repetition time, $2 \mathrm{~s}$ volume acquisition time, $24 \mathrm{~cm}$ field of view, $64 \times 64$ pixel matrix, and $3.75 \times 3.75 \mathrm{~mm}$ inplane voxels. Twenty-one sagittal slices covered the entire brain. Slice thickness was either 6.5 or $7.0 \mathrm{~mm}$ depending on brain width. Five runs of functional images were acquired, each composed of 80 whole-brain image volumes. Timing of scanner and task events is illustrated in Fig. 2.

\section{fMRI data analysis}

All image analysis was done with the AFNI software package (http://afni.nimh.nih.gov/afni) (Cox, 1996). Motion artifacts were minimized by within-participant registration of echoplanar image volumes. Estimates of the three translation and three rotation movements at each point in each time-series were computed during registration. Mean, linear trends, and 2nd-order trends were removed on a voxel-wise basis from each functional run, and the five runs were concatenated into a single series of 400 image volumes.

Image volumes were categorized according to the stimulus presented prior to each volume acquisition, and the entire series was then analyzed using multiple regression. Trials on which errors occurred were coded as such and treated as a separate condition of no interest. Normalized imageability ratings for each word were included as an independent regressor to identify brain areas modulated by imageability. Translation and rotation movement parameters estimated during image registration were included in the regression model to remove residual variance associated with motion-related changes in BOLD signal. Finally, the RTs on each 


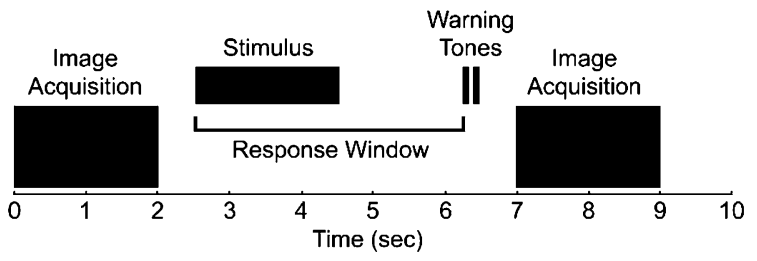

Fig. 2. Timing of MRI acquisition and task events.

trial (including error trials) were included in the regression model, after normalization of the RT values, to account for any variance due solely to time on task. Separate RT regressors were created for each of the three reading conditions. Since each RT regressor was normalized, each was orthogonal to the condition regressors and represented only within-condition variance in RT. The resulting parametric maps included coefficient (magnitude) and $t$-statistic parameters for each condition, for the imageability rating, and for each RT regressor. Contrasts between conditions (IrregularRegular, Irregular-Nonword, and Regular-Nonword) were then performed under a general linear model to identify voxels in which the BOLD response differed between conditions.

The resulting coefficient maps from each participant were linearly resampled in standard stereotaxic space (Talairach and Tournoux, 1988) to a voxel size of $1 \mathrm{~mm}^{3}$ and spatially smoothed with a 7-mm full-width-half-maximum Gaussian kernel to compensate for variance in anatomical structure. The smoothed coefficient maps were then subject to a random effects analysis comparing the coefficient values to a null hypothesis mean of zero across participants. Condition-specific RT maps were combined in a conjunction analysis to determine common areas modulated by RT independent of reading condition. All resulting group activation maps were thresholded at a voxel-wise 2-tailed probability of $P<0.001$ ( $\mid t$-deviate $\mid \geq 3.76$ ). Finally, Monte Carlo simulation was used to estimate the chance probability of spatially contiguous clusters of voxels passing this threshold. Clusters smaller than $450 \mu \mathrm{l}$ in the group maps were removed, resulting in a corrected 2-tailed probability threshold of $P<0.05$ for each group map.

\section{Results}

\section{Behavioral results}

All subjects were easily able to respond within the $3750-\mathrm{ms}$ response window on all trials. Response time (RT, correct trials only) and accuracy data are listed in Table 2. RT differed across conditions, as assessed by repeated-measures ANOVA on subject means $[F(2,46)=125.97 ; P<0.0001]$. Planned contrasts showed faster responses to Regular than Irregular words $[F(1,23)=49.61$; $P<0.0001]$, faster responses to Regular words than Nonwords $[F(1,23)=170.97 ; P<0.0001]$, and faster responses to Irregular words than Nonwords $[F(1,23)=107.92 ; P<0.0001]$.

Accuracy also differed across conditions $[F(2,46)=37.93 ; P<$ $0.0001]$. Planned contrasts showed a reliable advantage of Regular over Irregular words $[F(1,23)=56.33 ; P<0.0001]$, Regular words over Nonwords $[F(1,23)=15.12 ; P=0.001]$ and Nonwords over Irregular words $[F(1,23)=29.06 ; P<0.0001]$. Note that while there were differences in accuracy across conditions, only correct trials were included in the fMRI analysis, so accuracy was matched ( $100 \%$ in all conditions) in the fMRI analysis.

\section{fMRI results}

Tables in Appendix A list stereotaxic coordinates for activation peaks observed in the main contrasts of interest. Activations shown in the figures have been mapped to a representative 'inflated' brain surface using the FreeSurfer (http://surfer.nmr.mgh.harvard.edu) and CARET (http://brainvis.wustl.edu/caret) software packages (Dale et al., 1999; Van Essen et al., 2001).

\section{Activations relative to fixation}

Much of the brain was activated bilaterally during reading aloud compared to visual fixation, and the maps for the different conditions appeared qualitatively very similar. Fig. 3 shows an example map for the Nonword condition. Bilaterally activated regions included the calcarine cortex and occipital pole, large regions of ventral and dorsal extrastriate cortex, intraparietal sulcus (IPS), superior temporal primary and association auditory areas, lateral premotor and motor areas including the frontal eye field (FEF), inferior frontal gyrus (IFG) and adjacent middle frontal gyrus, insula, anterior cingulate gyrus and supplementary motor area (SMA), superior cerebellum (not shown), and basal ganglia.

'Deactivations' (i.e., higher signals during fixation) occurred bilaterally in the angular gyrus, posterior cingulate gyrus and precuneus, dorsal prefrontal cortex (centered on the superior frontal sulcus), and ventromedial frontal lobe; and unilaterally in the left anteromedial temporal lobe.

\section{Activations correlated with RT}

Inclusion of individual, trial-by-trial RT data in the activation model provides a powerful means of detecting areas where brain activity varies with RT. The analysis used condition-specific normalized RT values to represent within-condition RT variance. These maps were then combined in a conjunction analysis to identify brain areas modulated by RT regardless of stimulus condition (Fig. 4A). Many of the frontal and parietal regions activated during reading showed this sensitivity to time on task. These areas included the IFG and adjacent middle frontal gyrus, precentral sulcus and FEF, anterior insula, anterior cingulate gyrus, SMA, IPS, thalamus, and globus pallidus bilaterally; as well as left posterior temporal-occipital cortex in the posterior inferior temporal gyrus, posterior fusiform gyrus, and middle and inferior occipital gyri. Negative correlations with RT were observed in the left posterior cingulate gyrus and in the body and tail of the caudate nucleus bilaterally.

\section{Irregular vs. Regular words}

The contrast between Irregular and Regular words showed a more restricted set of activated regions (Fig. 4B). Notably, no areas showed stronger signals for Regular words. Stronger activity for Irregular words occurred in the IFG, adjacent middle frontal gyrus, and adjacent precentral sulcus bilaterally; anterior insula bilat-

Table 2

Task performance by condition

\begin{tabular}{lll}
\hline Condition & \% Accuracy (SD) & RT (SD) \\
\hline Irregular & $92.3(4.8)$ & $860(120)$ \\
Regular & $99.5(0.9)$ & $802(111)$ \\
Nonword & $96.8(3.3)$ & $966(158)$ \\
\hline
\end{tabular}

Mean response time (RT) given in milliseconds from the onset of the stimulus. 


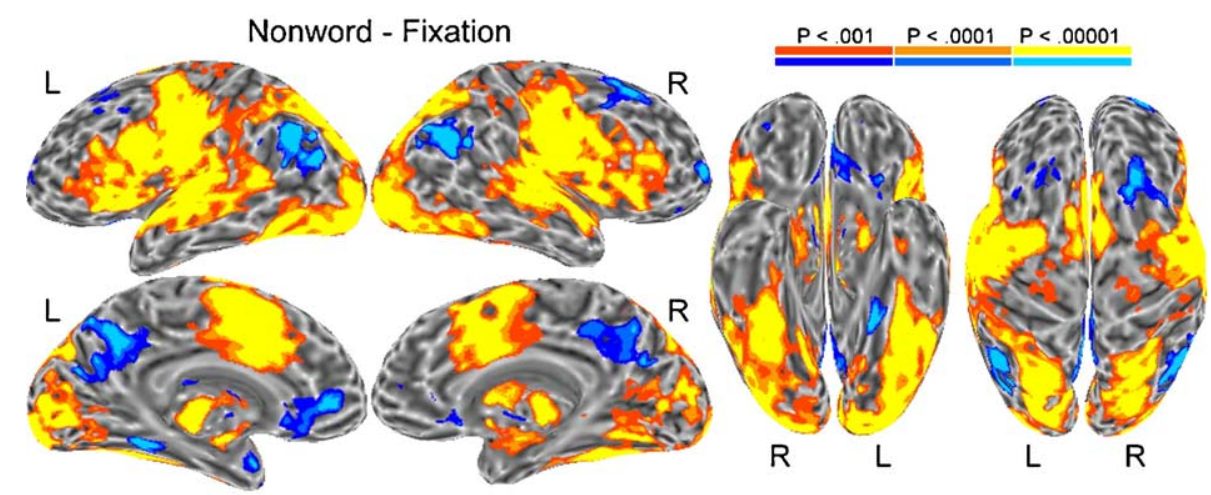

Fig. 3. Brain activation produced by Nonword naming relative to fixation. Left and right lateral and medial views of the inflated brain surface are shown in the left half of the figure, ventral and dorsal views in the right half. The color scale indicates voxel-wise probability values.

erally; anterior cingulate gyrus bilaterally; and left IPS. All of these areas had shown strong general effects of time on task in the RT map (Fig. 4A).

\section{Regular words vs. Nonwords}

If any of the areas activated by Irregular words relative to Regular words represent a lexical processing pathway, as postulated by the dual-route model, then these areas should also be activated to some degree by Regular words relative to Nonwords. This contrast showed greater activation by Regular words in a number of regions (yellow-red colors in Fig. 4C), but these regions did not overlap at all with those activated in the IrregularRegular contrast. Relatively greater activation for Regular words was observed in the left ventromedial temporal cortex (fusiform and parahippocampal gyri along the anterior collateral sulcus) and bilaterally in the angular gyrus, dorsal prefrontal cortex (centered on the superior frontal sulcus), posterior cingulate gyrus, precuneus, and ventromedial frontal cortex. A small focus occurred in the anterior right middle temporal gyrus.

Greater activation for Nonwords (blue colors in Fig. 4C) was seen bilaterally in the IFG and adjacent middle frontal gyrus, precentral sulcus and FEF, anterior insula, anterior cingulate gyrus, and IPS; and unilaterally in the left posterior inferior temporal-occipital region. These areas are strikingly similar to those modulated by RT (see Fig. 4A) and also overlap almost completely with areas activated by Irregular relative to Regular words. Thus, an almost identical network of brain regions was activated by both Nonwords and Irregular words relative to Regular words, and this network was modulated by RT independent of reading condition.

\section{Irregular words vs. Nonwords}

The contrast between Irregular words and Nonwords showed differential activation in several regions (Fig. 4D). Relatively greater activation for Irregular words was observed in many of the same areas observed for Regular words over Nonwords, including the angular gyrus bilaterally, left dorsal prefrontal cortex, left ventromedial temporal cortex along the anterior collateral sulcus, posterior cingulate gyrus, and ventromedial frontal cortex. Greater activation for Nonwords was seen in the left posterior IFG and adjacent precentral sulcus, left FEF, left posterior temporaloccipital cortex, bilateral anterior cingulate gyrus, and bilateral IPS. Once again, these areas activated by Nonwords overlapped almost entirely with those modulated by RT (Fig. 4A) and with those activated by Nonwords relative to Regular words (Fig. 4C).
There was, however, generally less activation for Nonwords relative to Irregular words than for Nonwords relative to Regular words.

\section{Imageability effects}

Imageability effects are of relevance for the interpretation of the angular gyrus and other regions activated more by words than nonwords (Figs. 4C and D). If these differences are due to activation of a non-semantic lexicon, as postulated in some versions of the dual-route model, these regions should not show sensitivity to word imageability, since both concrete and abstract words are represented similarly in the lexicon. We previously showed greater activation in these same regions, however, for concrete words relative to abstract words during a lexical decision task (Binder et al., in press).

Effects of word imageability were examined by incorporating individual item imageability ratings in the regression model. Positive correlations with imageability were observed in most of the areas activated by words relative to Nonwords, including the angular gyrus bilaterally, dorsal prefrontal cortex bilaterally, left ventromedial temporal cortex, and posterior cingulate gyrus bilaterally (Fig. 5). Ventromedial frontal cortex was not modulated by imageability. Negative correlations (stronger activation for less imageable words) occurred in the left IFG and adjacent precentral sulcus, and in the anterior cingulate gyrus bilaterally.

\section{Discussion}

Oral reading engages a variety of general and more specific processes, including primary vision and form perception, attention and other executive processes, orthographic to phonological translation, speech articulation, and speech perception. These systems - comprising large regions of visual, auditory, motor, premotor, prefrontal, and dorsal parietal cortex bilaterally-were activated in common during reading of Regular words, Irregular words, and Nonwords compared to a fixation baseline. More specific comparisons were designed to detect differences in brain activation as a function of spelling-sound regularity and lexicality. Complicating these analyses were significant differences in task difficulty across conditions, as indicated by differences in both RT and accuracy. These differences are not unique to the present study; they are consistently observed in experimental studies of word and nonword naming (Balota et al., 2004; Carr and Pollatsek, 1985; Seidenberg et al., 1984). Indeed, many effects of lexicality and 

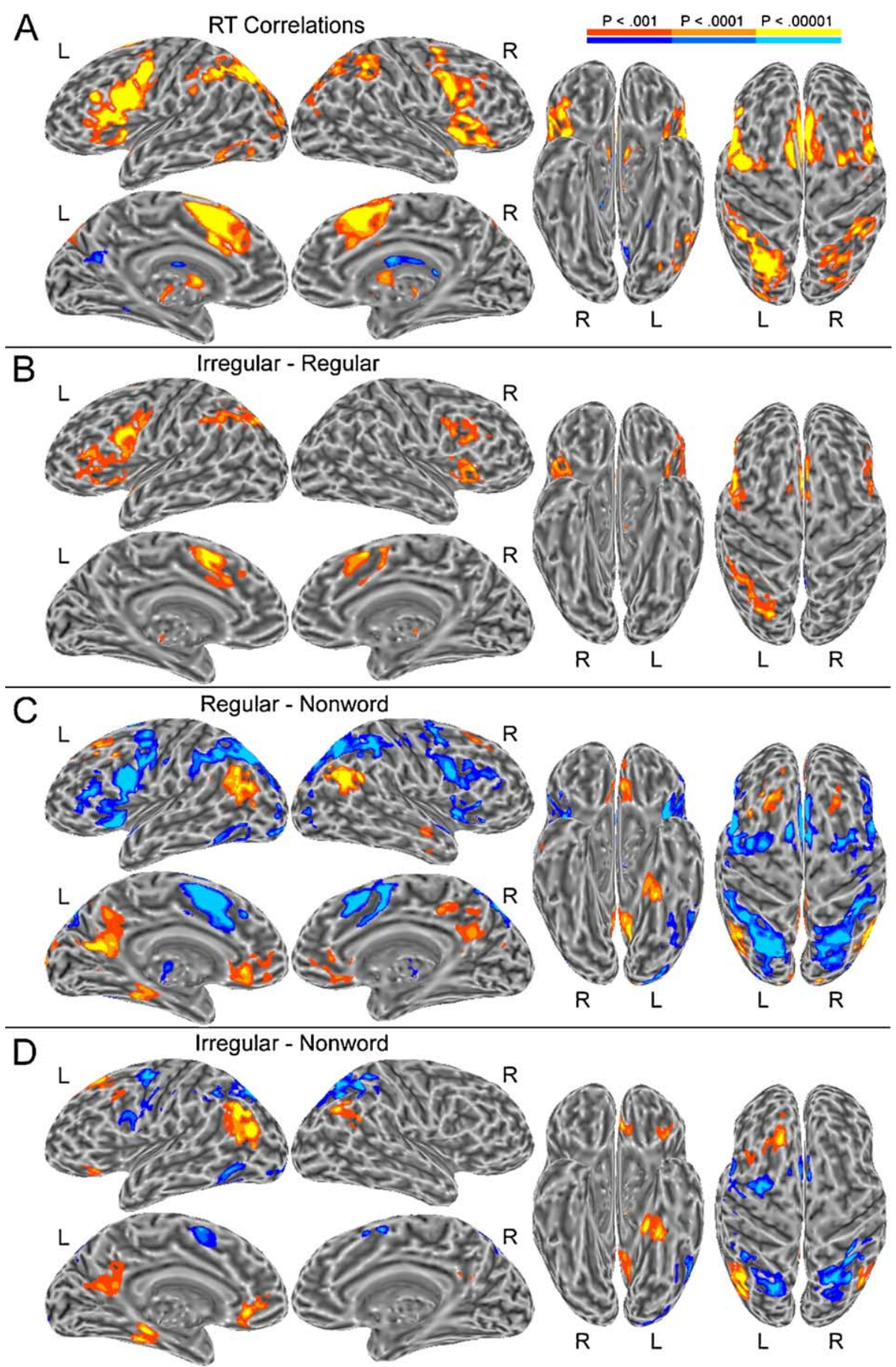

Fig. 4. (A) Brain activation positively correlated with RT. (B) Brain activation for the contrast between Irregular and Regular words. (C) Brain activation for the contrast between Regular words and Nonwords. (D) Brain activation for the contrast between Irregular words and Nonwords. Formatting as in Fig. 3.

spelling-sound regularity reported in previous imaging studies could have resulted from unmeasured differences in task difficulty. Our aim here was to test the feasibility of several models of word naming that focus on domain-specific orthographic, phonological, and semantic processes (Fig. 1). Approaching this goal using neurophysiological methods requires separation, as far as possible, of general effects on attention, working memory, decision, response selection, and monitoring processes from modulation of these domain-specific linguistic processes.
The novel strategy we pursued was to concurrently identify brain areas that are modulated by within-condition variation in RT during the naming task. Many of the frontal and parietal regions activated by the naming task showed this general sensitivity to time on task regardless of the particular reading condition. Many of these areas, including the IFG bilaterally, left precentral sulcus, and IPS, have been linked in prior studies to working memory processes (e.g., Barde and Thompson-Schill, 2002; Braver et al., 1997; D’Esposito et al., 1999; Honey et al., 2000; Jonides et al., 


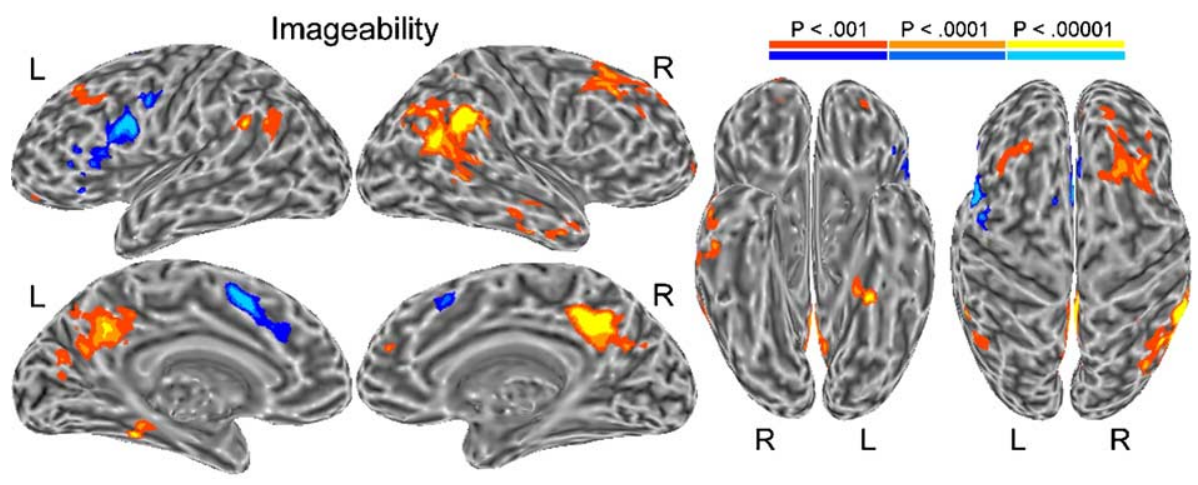

Fig. 5. Brain activation associated with word imageability. Formatting as in Fig. 3.

1997; Jonides et al., 1998; LaBar et al., 1999; Paulesu et al., 1993; Smith et al., 1998; Wager and Smith, 2003). Others, including the FEF, anterior cingulate gyrus, and IPS, are the principal components of a well-described frontoparietal attention network (e.g., Adler et al., 2001; Corbetta and Shulman, 2002; Gitelman et al., 1999; Kastner and Ungerleider, 2000; LaBar et al., 1999; Mesulam, 1999; Yantis et al., 2002). Other regions modulated by RT, including the IFG, anterior insula, and anterior cingulate gyrus bilaterally, have been linked with decision, response selection, and response monitoring processes (e.g., Badgaiyan and Posner, 1998; Binder et al., 2004; Botvinick et al., 1999; Braver et al., 2001; Carter et al., 1998; Horovitz et al., 2002; Krawczyk, 2002; Menon et al., 2001; Ullsperger and von Cramon, 2001; van Veen and Carter, 2002). All of these regions have been demonstrated previously to show activation correlated with RT (Binder et al., 2004; Binder et al., in press; Honey et al., 2000). Modulation of left posterior temporal-occipital cortex (posterior inferior temporal gyrus, inferior and middle occipital gyri) by RT warrants further discussion, since this region is unlikely to play a role in attentional control or other executive functions. These areas are considered ventral visual extrastriate cortex and are near both the 'visual word form area' in the left lateral fusiform gyrus and inferior temporal sulcus (Cohen et al., 2002; McCandliss et al., 2003) and the visual motion perception area MT (Beauchamp et al., 1997; Chawla et al., 1998; Zeki et al., 1991). Modulation of this region by RT was reported previously during a visual lexical decision task (Binder et al., in press), and this region was robustly activated in an fMRI study of covert shifting of spatial attention (Gitelman et al., 1999). One possibility is that attentional systems modulate the level of activity in early visual recognition networks located in these areas. RT may also be a rough index of how long subjects fixate the stimulus, which could determine activation level in these visual association areas. Another possibility, however, is that this region is modulated by demands on orthographic-to-phonological conversion processes. This account is considered in more detail later in discussing the 'exclusive' dual-route model.

An identical network of frontal, cingulate, insular, and dorsal parietal areas was activated in several of the contrasts between reading conditions. These areas showed stronger activation for Irregular compared to Regular words (Fig. 4B), as well as for Nonwords compared to Regular words (Fig. 4C) and Nonwords compared to Irregular words (Fig. 4D). This network of brain regions was thus generally activated in order of ascending task difficulty: least for Regular words, more for Irregular words, and most for Nonwords. These results are consistent with several prior studies that have shown relative activation of the IFG and adjacent areas by both nonwords and irregular words compared to regular words (Fiez et al., 1999; Herbster et al., 1997).

The direct comparisons between reading conditions also revealed another, distinct brain network activated by words (Regular and Irregular) relative to Nonwords. These areas included the angular gyrus, dorsal prefrontal cortex, posterior cingulate gyrus, and ventromedial frontal lobe bilaterally, and left ventromedial temporal cortex. This network has been strongly implicated in semantic processing in a number of previous studies (Binder and Price, 2001). For example, these regions show stronger activation during semantic than phonological tasks (Binder et al., 1999; Démonet et al., 1992; Mummery et al., 1998; Poldrack et al., 1999; Price et al., 1997; Roskies et al., 2001; Scott et al., 2003). They are activated more by words than nonwords during lexical decision (Binder et al., 2003; Binder et al., in press; Ischebeck et al., 2004) and more by concrete words than abstract words (Binder et al., in press). This network has also been repeatedly shown to 'deactivate' during active tasks relative to resting or passive stimulation conditions (Binder et al., 1999; Mazoyer et al., 2001; McKiernan et al., 2003; Raichle et al., 2001; Shulman et al., 1997). This latter effect was also clear in our contrasts between the naming conditions and passive fixation (Fig. 3), which showed 'deactivation' in a network almost identical to the one activated by words relative to nonwords.

In the following sections, we compare these patterns of activity with the predictions made by various models of word naming. Though these models remain somewhat underspecified at the neural level, we believe the imaging data rule out at least one account and offer some constraints for future development and modification of others.

\section{The 'exclusive' dual-route model}

How consistent are these data with the dual-route model of word naming? This depends on whether Irregular words are viewed as selectively activating the lexical pathway, as in the 'exclusive' version of the model, or are processed by both pathways. We believe our data are incompatible with an exclusive model. If Irregular words are processed only by the lexical pathway and not by the assembled phonology pathway, then Regular words should produce greater activation in the latter pathway than Irregular words. There were, however, no regions activated by Regular relative to Irregular words, which is inconsistent with an exclusive dual-route model. Furthermore, the exclusive model predicts much greater activation of this same assembled pathway by Nonwords than by Irregular words. 
Although there were several regions activated by Nonwords relative to Irregular words (blue areas in Fig. 4D), most of these areas were also activated more by Irregular words than Regular words. This pattern of activation (Nonword $>$ Irregular $>$ Regular) is clearly not compatible with the predicted response of an assembled phonology pathway.

What does this network of brain areas represent, then, if not a rule-based phonological assembly system? Rather than playing an exclusive role in one type of reading pathway, these frontal, anterior insula, anterior cingulate, and dorsal parietal regions appear to be modulated in a non-specific manner by task difficulty. Both spelling-sound regularity and lexicality can be understood as affecting pronunciation difficulty, though in somewhat different ways. Irregular words contain grapheme-phoneme correspondences that are unusual or unique; in essence, these correspondences are encountered much less frequently than regular graphemephoneme mappings. In the case of Nonwords, the string of letters taken as a whole is unique, so the grapheme-phoneme mappings for the string as a whole are less familiar. In addition, Nonwords do not activate lexical or semantic representations that could assist in producing a phonological output. In both cases, the relative unfamiliarity of the particular correspondence makes the mapping process less efficient, resulting in an increased load on attentional (FEF, IPS, anterior cingulate), working memory (IFG, precentral gyrus, IPS), decision (IFG, anterior cingulate gyrus, anterior insula), and response monitoring (anterior cingulate gyrus) mechanisms. Activation of these regions is therefore consistent with the expected and observed differences in task difficulty between conditions, and not indicative of a specialized route for rule-based phonological assembly.

A possible exception to this interpretation concerns the left inferior temporal-occipital cortex, which showed greater activation for Nonwords than for either Regular or Irregular words, but no difference between Regular and Irregular words. This pattern could represent an assembled phonology (GPC) pathway that is particularly activated by nonwords. Indeed, activation of this region by nonwords relative to words in a few prior studies has been so interpreted (Mechelli et al., 2003; Paulesu et al., 2000; Xu et al., 2001). While this interpretation cannot be entirely discounted, the same pattern of activation across contrasts occurred in the left FEF and right IPS, neither of which showed differences between Regular and Irregular words. Since it is unlikely that either of these regions process grapheme or phoneme representations, a parsimonious explanation is that these three regions showed no difference between Irregular and Regular words because these conditions were closer in terms of RT $(58 \mathrm{~ms}$ difference) than were the Nonword and Irregular word (106 ms difference) or Nonword and Regular word (164 ms difference) contrasts.

Why, then, were there other regions - in the IFG and anterior insula bilaterally - that did show differences between Irregular and Regular words (Fig. 4B) but no differences between Nonwords and Irregular words (Fig. 4D)? These dissociations deserve further detailed investigation, but the likely answer is that 'task difficulty' is not a simple, unitary phenomenon. For example, while the word conditions were closer to each other in terms of RT than either condition was to the Nonword condition, this was not true for the accuracy measure, which was much lower for Irregular words compared to the other conditions. While error trials were removed from the analysis, it is still likely that Irregular words placed the greatest demands on decision, response selection, and error monitoring processes, accounting for additional activation in certain frontal regions for the Irregular-Regular contrast.

A final result that is incompatible with an exclusive dual-route model is the finding that areas activated by Irregular words relative to Nonwords (angular gyrus, dorsal prefrontal cortex, left anterior collateral sulcus, posterior cingulate gyrus, ventromedial frontal cortex) are activated equally well by Regular words. According to dual-route theory, these areas must represent the lexical pathway, which is predicted to be activated by words but not (as much) by nonwords. According to the exclusive dual-route model, this pathway should be activated more by Irregular than Regular words, since at least some Regular words are processed by the assembled phonology route. This is predicted to be the case especially with lower-frequency regular words such as those used in this study. Thus, the finding of equivalent activation in these regions by Regular and Irregular words (i.e., no difference in these regions in the direct comparison, Fig. 4B) is incompatible with an exclusive version of the dual-route model.

\section{The 'parallel' dual-route model}

In more recent, connectionist versions of the dual-route model, Irregular words (and Regular words) are processed in parallel by both the lexical and assembled phonology routes (Coltheart et al., 1993; Coltheart et al., 2001). Both pathways provide input to a common phoneme selection system comprised of position-specific phoneme units. In the case of Regular words, the inputs received by these phoneme units from the lexical and assembled pathways are congruent, and activation of the correct target phoneme units ensues without conflict. In the case of Irregular words, the inputs to the phoneme units from lexical and assembled pathways are partly incongruent, with resulting delay in activation of the target phonemes.

In contrast to the exclusive dual-route model, the parallel model does not predict differences in activation of the two reading routes by Regular and Irregular words, since both word types activate both pathways. The only difference occurs at the final stage of phoneme selection, which proceeds more slowly and with more competition between alternatives in the case of Irregular words. Thus, the model is compatible with our results showing greater activation for Irregular words in brain areas associated with attention and executive processes. Similarly, since activation of these brain regions is purely a function of pronunciation difficulty and not related to any particular reading mechanism, Nonwordswhich are the most difficult to pronounce-produce the strongest activation.

Activation of the angular gyrus and other regions by both Irregular and Regular words is also compatible with the parallel dual-route model. According to this model, all words activate word units in the lexical pathway, which are activated weakly or not at all by Nonwords. According to the parallel dual-route model, these regions are the neural correlates of the orthographic and phonological lexicons that enable whole-word naming.

\section{The 'triangle' model}

The results are also compatible with connectionist models that contain no word units, but instead compute print-to-sound mappings through interactive activation of non-lexical orthographic, phonological, and semantic units (Harm and Seidenberg, 2004; Plaut et al., 1996; Seidenberg and McClelland, 1989). Like 
the parallel dual-route model, the triangle model postulates activation of all parts of the reading system by both Irregular and Regular words. Irregular words are named more slowly than Regular words because of conflicting input to the phonological system from semantic and orthographic systems, and because of relatively stronger connections from orthography to phonology in the case of Regular words. Both Irregular and Regular words produce stronger input to the semantic system than Nonwords, since connections from orthography to semantics are relatively weak for Nonwords.

Thus, both the triangle model and the parallel dual-route model are compatible with our finding of relatively little activation difference between Irregular and Regular words, and with the greater activation in attention and executive systems as a function of pronunciation difficulty. Both models also predict the observation that some brain areas respond more to words than to Nonwords.

\section{Lexicon or semantics?}

The preceding discussion serves to emphasize an important point, that the chief distinction between the parallel dual-route and triangle models of word naming (at least as these are currently formulated) is whether Irregular word naming is enabled by word units or by semantic units. The concept of a non-semantic lexicon or 'list of words in the brain' remains an essential feature of all dual-route models, while the triangle model contains no units representing individual words or word-forms. In place of the lexicon in the triangle model are distributed representations of word meaning. Activation of a given set of these units is analogous to accessing the meaning of a word, which can then be mapped directly onto a phonological representation without an intervening lexicon. Given this critical distinction between the models, it is important to consider the response properties of the angular gyrus and other regions activated by word relative to nonword naming. Do these regions behave as though they are processing lexical status or processing meaning?

As discussed above, all of the regions showing activation for words relative to Nonwords in the current study have been associated with semantic processing in previous studies (Binder et al., 1999, 2003, in press; Démonet et al., 1992; Mummery et al., 1998; Poldrack et al., 1999; Price et al., 1997; Roskies et al., 2001; Scott et al., 2003). In a previous lexical decision experiment (Binder et al., 2003), we tested the hypothesis that activation for words compared to nonwords in these regions might be due to activation of word units. This study manipulated the orthographic neighborhood size of the word and nonword stimuli, i.e., the number of words that are orthographically similar to (differing by one letter from) the stimulus (Coltheart et al., 1977). Increasing the neighborhood size of a stimulus affects performance on speeded visual recognition tasks (Andrews, 1989; Carreiras et al., 1997; Coltheart et al., 1977; Forster and Shen, 1996; Grainger and Jacobs, 1996; Huntsman and Lima, 1996; Sears et al., 1995), and many theorists have proposed that these effects represent partial activation of the word units in the lexicon that represent the neighbors of the stimulus. That is, reading the word TAIL will cause partial activation of the word nodes for BAIL, FAIL, MAIL, NAIL, PAIL, RAIL, SAIL, TOIL, and TALL. Thus, stimuli with many neighbors should produce greater activation in the lexicon than words with few neighbors (e.g., SIGN). The results of this prior study, however, offered no support for this hypothesis. No regions showed increased activity for large-neighborhood relative to small-neighborhood words. In fact, many of the regions activated by words compared to nonwords showed the opposite effect-greater activation for small-neighborhood words. This pattern was attributed to additional activation of semantic information for small-neighborhood words as compensation for the lower orthographic familiarity of these items (Binder et al., 2003). These data thus provide no evidence for activation of wordlevel codes.

Also supporting a semantic account is the modulation of these regions by word imageability. Imageability is a semantic property, so there seems little reason to expect differential activation of nonsemantic word codes by this factor, provided that other lexical variables (e.g., word frequency, neighborhood size) are controlled. The positive correlation between word imageability and activation in the angular gyri, dorsal prefrontal cortex, left ventromedial temporal cortex, and posterior cingulate gyrus therefore argues for a semantic interpretation of the processes carried out in these areas. It should be noted that this manipulation was not a strong one, since word naming is a relatively shallow task that does not overtly require processing of semantic information, and imageability is only one of many possible semantic factors that could determine the level of activation in these regions. The fact that imageability effects were nevertheless observed is compelling evidence for involvement of these brain regions in aspects of semantic retrieval.

Finally, the 'deactivation' of these regions by active tasks relative to conscious resting and passive stimulation conditions (Fig. 3) can also be seen as consistent with a semantic account. Both intuition and empirical evidence suggest that the conscious 'resting' state is a highly active condition involving ongoing retrieval of conceptual and autobiographical knowledge, problemsolving, and planning (Andreasen et al., 1995; Antrobus et al., 1966; Binder et al., 1999; James, 1890; Mazoyer et al., 2001; McGuire et al., 1996; McKiernan et al., 2003; Pope and Singer, 1976; Shulman et al., 1997; Singer, 1993; Stark and Squire, 2001; Teasdale et al., 1993). Given the complex and highly integrative nature of the conceptual processing that occurs during 'rest', it is not surprising that regions responsible for this processing would be less engaged by single words and nonwords that provide at best only limited semantic input.

\section{Summary}

Much of the discussion in the functional neuroimaging literature concerning dual-route models of word naming has focused, either implicitly or explicitly, on what we refer to as the 'exclusive' version of the theory. In this version, words are processed either entirely or predominantly by one of the putative routes to the exclusion of the other. In this fMRI study, we found no support for this model and much evidence to contradict it. For example, there was no differential activation consistent with the predicted response of a phonological assembly route (nonword $>$ regular word $>$ irregular word), and the 'lexical route' regions activated more by words than nonwords were equally active for irregular and regular words.

These findings are consistent, however, with either a parallel, interactive version of the dual-route model (Coltheart et al., 1993, 2001) or with a single-mechanism 'triangle' model lacking word units (Plaut et al., 1996; Seidenberg and McClelland, 1989). The chief distinction between these theories lies in whether the indirect pathway to phonology is mediated by word codes or by semantic 
codes. The available evidence suggests that these 'lexical route' regions are modulated by semantic factors and not by lexical neighborhood size, arguing for a semantic interpretation, though this is clearly an issue warranting further investigation.

\section{Acknowledgments}

Supported by National Institute of Neurological Diseases and Stroke grant R01 NS33576, National Institute of Mental Health grant P01 MH51358, and National Institutes of Health General Clinical Research Center grant M01 RR00058. We thank E.T. Possing, T.E. Prieto, and B.D. Ward for technical assistance, and several anonymous reviewers for helpful suggestions.

\section{Appendix A}

Location of activation peaks in the atlas of Talairach and Tournoux (1988)

\begin{tabular}{|c|c|c|c|c|}
\hline Location & $x$ & $y$ & $z$ & $Z$ score \\
\hline \multicolumn{5}{|l|}{ Nonword $>$ fixation } \\
\hline \multicolumn{5}{|l|}{ Medial frontal } \\
\hline L SMA & -5 & -3 & 58 & 7.526 \\
\hline $\mathrm{L}$ ant cingulate $\mathrm{g}$ & -7 & 12 & 30 & 6.348 \\
\hline $\mathrm{L}$ cingulate $\mathrm{g}$ & -9 & -12 & 36 & 5.192 \\
\hline $\mathrm{L}$ cingulate $\mathrm{g}$ & -7 & -2 & 32 & 4.847 \\
\hline $\mathrm{R}$ ant cingulate $\mathrm{g}$ & 15 & 10 & 32 & 5.536 \\
\hline $\mathrm{R}$ ant cingulate $\mathrm{g}$ & 5 & 6 & 28 & 5.490 \\
\hline $\mathrm{R}$ ant cingulate $\mathrm{g}$ & 10 & 19 & 21 & 5.117 \\
\hline \multicolumn{5}{|l|}{ Lateral frontal } \\
\hline $\mathrm{L}$ precentral $\mathrm{s}$ & -42 & 2 & 27 & 6.911 \\
\hline L FEF & -22 & -10 & 46 & 5.770 \\
\hline L pars opercularis & -48 & 8 & 0 & 6.119 \\
\hline $\mathrm{L}$ pars triangularis & -49 & 23 & 16 & 4.623 \\
\hline $\mathrm{L}$ pars triangularis & -47 & 29 & 4 & 4.359 \\
\hline $\mathrm{L}$ mid frontal $\mathrm{g}$ & -40 & 18 & 25 & 5.202 \\
\hline $\mathrm{L}$ mid frontal $\mathrm{g}$ & -50 & 41 & 11 & 4.534 \\
\hline $\mathrm{R}$ precentral s & 54 & -11 & 26 & 7.561 \\
\hline $\mathrm{R}$ precentral $\mathrm{s}$ & 41 & 6 & 23 & 5.297 \\
\hline $\mathrm{R}$ precentral $\mathrm{s}$ & 49 & 4 & 33 & 5.092 \\
\hline R FEF & 28 & -8 & 48 & 4.539 \\
\hline $\mathrm{R}$ pars opercularis & 46 & 12 & 0 & 6.344 \\
\hline $\mathrm{R}$ pars triangularis & 43 & 25 & 10 & 5.825 \\
\hline \multicolumn{5}{|l|}{ Anterior insula } \\
\hline $\mathrm{L}$ ant insula & -35 & 22 & 5 & 6.463 \\
\hline $\mathrm{R}$ ant insula & 27 & 10 & 5 & 5.823 \\
\hline \multicolumn{5}{|l|}{ Central } \\
\hline $\mathrm{L}$ precentral $\mathrm{g}$ & -53 & -11 & 27 & 7.089 \\
\hline L central s & -45 & -17 & 34 & 6.711 \\
\hline L central s & -57 & -15 & 14 & 6.593 \\
\hline L central s & -55 & -12 & 42 & 6.524 \\
\hline $\mathrm{L}$ precentral $\mathrm{g}$ & -64 & -12 & 5 & 5.820 \\
\hline L precentral $\mathrm{g}$ & -53 & -9 & 1 & 5.717 \\
\hline $\mathrm{L}$ insula & -31 & -13 & 14 & 5.022 \\
\hline $\mathrm{R}$ precentral $\mathrm{g}$ & 58 & -8 & 15 & 7.188 \\
\hline $\mathrm{R}$ central s & 51 & -13 & 39 & 6.793 \\
\hline $\mathrm{R}$ central $\mathrm{s}$ & 48 & -20 & 50 & 5.080 \\
\hline $\mathrm{R}$ central $\mathrm{s}$ & 34 & -24 & 56 & 4.504 \\
\hline $\mathrm{R}$ central s & 17 & -31 & 48 & 4.274 \\
\hline \multicolumn{5}{|l|}{ Superior parietal } \\
\hline L IPS & -24 & -65 & 39 & 6.911 \\
\hline L IPS & -26 & -79 & 20 & 5.970 \\
\hline L IPS & -33 & -52 & 41 & 5.285 \\
\hline
\end{tabular}

Appendix A (continued)

\begin{tabular}{|c|c|c|c|c|}
\hline Location & $x$ & $y$ & $z$ & $Z$ score \\
\hline \multicolumn{5}{|l|}{ Nonword $>$ fixation } \\
\hline \multicolumn{5}{|l|}{ Superior parietal } \\
\hline L dorsal SMG & -42 & -41 & 34 & 5.166 \\
\hline L SPL & -26 & -66 & 54 & 4.923 \\
\hline L SPL & -19 & -80 & 44 & 4.474 \\
\hline L SPL & -36 & -57 & 51 & 4.467 \\
\hline R IPS & 25 & -68 & 46 & 6.066 \\
\hline R IPS & 25 & -71 & 23 & 5.860 \\
\hline R IPS & 30 & -57 & 43 & 5.331 \\
\hline R SPL & 16 & -76 & 38 & 4.918 \\
\hline \multicolumn{5}{|l|}{ Superior temporal } \\
\hline L HG & -35 & -26 & 10 & 6.256 \\
\hline L HG & -37 & -21 & 0 & 6.100 \\
\hline L sup temporal g & -46 & -41 & 11 & 5.276 \\
\hline $\mathrm{R}$ sup temporal $\mathrm{g}$ & 53 & -12 & -1 & 6.444 \\
\hline $\mathrm{R}$ sup temporal $\mathrm{s}$ & 47 & -30 & 6 & 6.144 \\
\hline \multicolumn{5}{|l|}{ Occipital } \\
\hline $\mathrm{L}$ fusiform $\mathrm{g}$ & -39 & -50 & -19 & 7.246 \\
\hline $\mathrm{L}$ inf occipital $\mathrm{g}$ & -27 & -91 & -7 & 7.243 \\
\hline $\mathrm{L}$ inf occipital $\mathrm{g}$ & -15 & -96 & -9 & 6.214 \\
\hline $\mathrm{L}$ inf occipital $\mathrm{g}$ & -36 & -82 & -12 & 6.084 \\
\hline $\mathrm{L}$ calcarine $\mathrm{s}$ & -5 & -83 & 6 & 5.847 \\
\hline L sup occipital g & -22 & -79 & 31 & 5.778 \\
\hline $\mathrm{L}$ fusiform $\mathrm{g}$ & -22 & -67 & -15 & 5.085 \\
\hline $\mathrm{L}$ fusiform $\mathrm{g}$ & -17 & -64 & -5 & 4.342 \\
\hline L occipital pole & -4 & -101 & -13 & 4.322 \\
\hline $\mathrm{R}$ occipital pole & 21 & -93 & -6 & 6.246 \\
\hline $\mathrm{R}$ inf occipital $\mathrm{g}$ & 26 & -84 & -7 & 6.230 \\
\hline $\mathrm{R}$ calcarine $\mathrm{s}$ & 11 & -74 & 9 & 5.734 \\
\hline $\mathrm{R}$ mid occipital $\mathrm{g}$ & 39 & -80 & -3 & 5.588 \\
\hline $\mathrm{R}$ mid occipital $\mathrm{g}$ & 27 & -80 & 9 & 5.198 \\
\hline $\mathrm{R}$ inf occipital $\mathrm{g}$ & 34 & -86 & -15 & 5.109 \\
\hline $\mathrm{R}$ cuneus & 18 & -78 & 25 & 5.066 \\
\hline $\mathrm{R}$ fusiform $\mathrm{g}$ & 45 & -53 & -13 & 5.077 \\
\hline $\mathrm{R}$ fusiform $\mathrm{g}$ & 33 & -60 & -6 & 4.964 \\
\hline $\mathrm{R}$ lingual $\mathrm{g}$ & 7 & -64 & -3 & 4.754 \\
\hline $\mathrm{R}$ fusiform $\mathrm{g}$ & 45 & -72 & -14 & 4.566 \\
\hline $\mathrm{R}$ fusiform $\mathrm{g}$ & 46 & -43 & -9 & 4.546 \\
\hline $\mathrm{R}$ occipital pole & 6 & -95 & -11 & 4.378 \\
\hline \multicolumn{5}{|l|}{ Ventral temporal } \\
\hline $\mathrm{L}$ inf temporal $\mathrm{s}$ & -41 & -64 & -8 & 5.504 \\
\hline L parahippocampus & -35 & -7 & -22 & 4.114 \\
\hline R hippocampus & 30 & -13 & -6 & 5.706 \\
\hline $\mathrm{R}$ amygdala & 30 & -3 & -15 & 5.190 \\
\hline $\mathrm{R}$ inf temporal $\mathrm{g}$ & 57 & -64 & -11 & 3.919 \\
\hline \multicolumn{5}{|l|}{ Subcortical } \\
\hline L thalamus & -16 & -16 & 5 & 7.596 \\
\hline L putamen & -19 & -6 & 14 & 6.387 \\
\hline L putamen & -26 & 8 & 11 & 4.942 \\
\hline $\mathrm{L}$ claustrum & -30 & -3 & 9 & 4.915 \\
\hline $\mathrm{R}$ thalamus & 14 & -21 & 1 & 7.277 \\
\hline $\mathrm{R}$ globus pallidus & 17 & -3 & 10 & 5.833 \\
\hline $\mathrm{R}$ internal capsule & 27 & -27 & 10 & 5.742 \\
\hline $\mathrm{R}$ thalamus & 22 & -14 & 17 & 5.654 \\
\hline \multicolumn{5}{|l|}{ Cerebellum } \\
\hline L sup cerebellum & -17 & -53 & -20 & 6.415 \\
\hline L sup cerebellum & -32 & -68 & -23 & 6.044 \\
\hline $\mathrm{L}$ ant cerebellum & -28 & -30 & -28 & 4.927 \\
\hline $\mathrm{L}$ post cerebellum & -24 & -84 & -24 & 4.073 \\
\hline $\mathrm{R}$ sup cerebellum & 20 & -48 & -19 & 6.453 \\
\hline $\mathrm{R}$ sup cerebellum & 31 & -54 & -24 & 5.918 \\
\hline $\mathrm{R}$ inf cerebellum & 14 & -60 & -38 & 4.808 \\
\hline $\mathrm{R}$ ant cerebellum & 28 & -24 & -28 & 4.694 \\
\hline
\end{tabular}


Appendix A (continued)

\begin{tabular}{lrrrr}
\hline Location & $x$ & $y$ & $z$ & $Z$ score \\
\hline Nonword $>$ fixation & & & & \\
Cerebellum & & & & \\
$\quad$ R sup cerebellum & 22 & -70 & -16 & 4.536 \\
$\quad$ R inf cerebellum & 22 & -51 & -46 & 4.531 \\
$\quad$ Vermis & 1 & -54 & -18 & 4.458 \\
Brainstem & & & & \\
$\quad$ L midbrain & -7 & -20 & -4 & 6.433
\end{tabular}

Fixation $>$ nonword

Angular gyrus

\begin{tabular}{|c|c|c|c|c|}
\hline $\mathrm{L}$ angular $\mathrm{g}$ & -54 & -66 & 30 & -5.775 \\
\hline $\mathrm{L}$ angular $\mathrm{g}$ & -45 & -72 & 33 & -5.752 \\
\hline $\mathrm{R}$ angular $\mathrm{g}$ & 45 & -58 & 24 & -5.718 \\
\hline $\mathrm{R}$ angular $\mathrm{g}$ & 41 & -75 & 36 & -5.476 \\
\hline $\mathrm{R}$ angular $\mathrm{g}$ & 56 & -65 & 28 & -5.115 \\
\hline \multicolumn{5}{|l|}{ Dorsal prefrontal } \\
\hline L sup frontal s & -25 & 19 & 44 & -3.990 \\
\hline L sup frontal s & -20 & 52 & 15 & -3.806 \\
\hline $\mathrm{L}$ mid frontal $\mathrm{g}$ & -35 & 13 & 42 & -3.693 \\
\hline $\mathrm{L}$ sup frontal $\mathrm{g}$ & -20 & 28 & 48 & -3.630 \\
\hline $\mathrm{L}$ mid frontal $\mathrm{g}$ & -28 & 48 & 3 & -3.438 \\
\hline $\mathrm{R}$ sup frontal $\mathrm{s}$ & 27 & 48 & 9 & -5.069 \\
\hline $\mathrm{R}$ sup frontal $\mathrm{s}$ & 22 & 23 & 41 & -5.063 \\
\hline $\mathrm{R}$ sup frontal $\mathrm{g}$ & 18 & 54 & 13 & -4.444 \\
\hline $\mathrm{R}$ mid frontal $\mathrm{g}$ & 39 & 10 & 48 & -4.159 \\
\hline $\mathrm{R}$ sup frontal $\mathrm{g}$ & 17 & 45 & 6 & -3.668 \\
\hline $\mathrm{R}$ mid frontal $\mathrm{g}$ & 33 & 18 & 56 & -3.573 \\
\hline \multicolumn{5}{|l|}{ Ventromedial frontal } \\
\hline $\mathrm{L}$ pars orbitalis & -29 & 10 & -18 & -5.050 \\
\hline $\mathrm{L}$ vent cingulate $\mathrm{g}$ & -12 & 34 & 3 & -4.880 \\
\hline $\mathrm{L}$ vent cingulate $\mathrm{g}$ & -8 & 21 & -6 & -4.176 \\
\hline \multicolumn{5}{|l|}{ osterior medial } \\
\hline $\mathrm{L}$ precuneus & -7 & -55 & 34 & -5.000 \\
\hline $\mathrm{L}$ post cingulate $\mathrm{g}$ & -11 & -67 & 22 & -4.771 \\
\hline $\mathrm{R}$ post cingulate $\mathrm{g}$ & 9 & -58 & 22 & -4.615 \\
\hline $\mathrm{R}$ post cingulate $\mathrm{g}$ & 5 & -45 & 36 & -4.392 \\
\hline \multicolumn{5}{|l|}{ Гemporal } \\
\hline L hippocampus & -30 & -39 & -3 & -5.173 \\
\hline $\begin{array}{l}\text { L temporal pole } \\
\text { Subcortical }\end{array}$ & -33 & 15 & -26 & -3.619 \\
\hline$L$ caudate $n$ & -21 & -23 & 24 & -4.118 \\
\hline L caudate $n$ & -22 & -39 & 21 & -4.050 \\
\hline
\end{tabular}

Positive RT correlations

Medial frontal

\begin{tabular}{lrrrr} 
L SMA & -3 & 3 & 52 & 5.879 \\
L ant cingulate g & -9 & 10 & 39 & 5.646 \\
L ant cingulate g & -9 & 22 & 27 & 4.782 \\
L sup frontal g & -4 & 20 & 49 & 5.408 \\
R SMA & 13 & 9 & 63 & 4.473 \\
R ant cingulate g & 7 & 13 & 42 & 5.663 \\
R ant cingulate g & 10 & 21 & 24 & 4.435 \\
ateral frontal & & & & \\
L FEF & -32 & -7 & 43 & 5.450 \\
L precentral s & -41 & -2 & 28 & 6.255 \\
L precentral s & -50 & 3 & 21 & 5.862 \\
L pars opercularis & -54 & 11 & 12 & 5.059 \\
L pars opercularis & -42 & 15 & 3 & 4.695 \\
L inf frontal s & -41 & 13 & 23 & 7.310 \\
R precentral g & 49 & -13 & 39 & 3.480 \\
R FEF & 26 & -7 & 47 & 5.003 \\
R precentral s & 45 & 5 & 29 & 5.358 \\
R precentral s & 33 & -5 & 34 & 5.068 \\
\hline
\end{tabular}

Appendix A (continued)

\begin{tabular}{|c|c|c|c|c|}
\hline Location & $x$ & $y$ & $z$ & $Z$ score \\
\hline \multicolumn{5}{|l|}{ Positive RT correlations } \\
\hline \multicolumn{5}{|l|}{ Lateral frontal } \\
\hline $\mathrm{R}$ pars opercularis & 44 & 16 & 0 & 5.191 \\
\hline $\mathrm{R}$ pars opercularis & 57 & 12 & 8 & 3.789 \\
\hline $\mathrm{R}$ pars triangularis & 46 & 20 & 12 & 5.587 \\
\hline $\mathrm{R}$ pars orbitalis & 41 & 24 & -7 & 5.093 \\
\hline $\mathrm{R}$ inf frontal $\mathrm{s}$ & 33 & 20 & 22 & 4.024 \\
\hline $\mathrm{R}$ mid frontal $\mathrm{g}$ & 41 & 22 & 32 & 4.088 \\
\hline \multicolumn{5}{|l|}{ Anterior insula } \\
\hline $\mathrm{L}$ ant insula & -33 & 11 & 7 & 4.928 \\
\hline $\mathrm{R}$ ant insula & 29 & 13 & 7 & 5.326 \\
\hline \multicolumn{5}{|l|}{ Superior parietal } \\
\hline L IPS & -27 & -63 & 39 & 6.045 \\
\hline L IPS & -37 & -46 & 36 & 5.632 \\
\hline L IPS & -27 & -48 & 35 & 5.208 \\
\hline L SPL & -36 & -68 & 53 & 4.844 \\
\hline L SPL & -19 & -81 & 51 & 4.525 \\
\hline L SPL & -20 & -87 & 43 & 4.204 \\
\hline L SPL & -45 & -56 & 54 & 3.694 \\
\hline L IPS & -37 & -56 & 46 & 4.830 \\
\hline L IPS/dorsal SMG & -48 & -40 & 39 & 4.822 \\
\hline L dorsal SMG & -53 & -32 & 34 & 4.136 \\
\hline R IPS/dorsal SMG & 40 & -44 & 36 & 5.193 \\
\hline R IPS & 26 & -75 & 30 & 4.615 \\
\hline R IPS & 25 & -65 & 51 & 4.562 \\
\hline R IPS & 27 & -62 & 40 & 4.462 \\
\hline R SPL & 36 & -58 & 53 & 4.480 \\
\hline R SPL & 13 & -82 & 47 & 3.940 \\
\hline R SPL & 24 & -81 & 46 & 3.907 \\
\hline R SPL & 25 & -87 & 35 & 3.778 \\
\hline R SPL & 17 & -69 & 46 & 3.692 \\
\hline \multicolumn{5}{|l|}{ Lateral occipital } \\
\hline L mid occipital $g$ & -30 & -91 & 11 & 4.521 \\
\hline $\mathrm{L}$ inf occipital $\mathrm{g}$ & -36 & -74 & -7 & 4.503 \\
\hline L mid occipital g & -24 & -78 & 19 & 4.377 \\
\hline L mid occipital g & -28 & -92 & 24 & 3.968 \\
\hline $\mathrm{L}$ inf occipital $\mathrm{g}$ & -52 & -74 & -10 & 3.890 \\
\hline L sup occipital g & -24 & -85 & 32 & 3.590 \\
\hline $\mathrm{R}$ mid occipital $\mathrm{g}$ & 27 & -79 & 15 & 3.850 \\
\hline $\mathrm{R}$ mid occipital g & 36 & -86 & 14 & 3.793 \\
\hline \multicolumn{5}{|l|}{ Posterior temporal } \\
\hline $\mathrm{L}$ inf temporal $\mathrm{s}$ & -42 & -55 & -10 & 4.558 \\
\hline \multicolumn{5}{|l|}{ Superior temporal } \\
\hline $\mathrm{R}$ sup temporal $\mathrm{g}$ & 51 & 17 & -8 & 4.795 \\
\hline \multicolumn{5}{|l|}{ Subcortical } \\
\hline L globus pallidus & -13 & 4 & 6 & 4.848 \\
\hline $\mathrm{L}$ thalamus & -8 & -16 & 2 & 3.995 \\
\hline $\mathrm{R}$ globus pallidus & 14 & -2 & 3 & 5.629 \\
\hline $\mathrm{R}$ thalamus & 11 & -12 & -2 & 4.080 \\
\hline \multicolumn{5}{|l|}{ Brainstem } \\
\hline Midbrain & 1 & -24 & -12 & 3.666 \\
\hline Midbrain & 1 & -23 & 1 & 4.367 \\
\hline
\end{tabular}

Negative RT correlations

Posterior medial

L post cingulate $g$

\begin{tabular}{rrrr}
-10 & -56 & 21 & -4.470 \\
-17 & -12 & 29 & -4.761 \\
-31 & -40 & 20 & -4.643 \\
-20 & -44 & 22 & -4.378 \\
-32 & -41 & 0 & -4.297 \\
-29 & -24 & 24 & -3.732 \\
-18 & 1 & 24 & -3.438 \\
\hline
\end{tabular}


Appendix A (continued)

\begin{tabular}{lrrrr}
\hline Location & \multicolumn{1}{c}{$y$} & \multicolumn{1}{c}{$z$} & $Z$ score \\
\hline Negative RT correlations & & & & \\
Subcortical & & & & \\
R caudate n & 12 & -2 & 24 & -4.995 \\
R caudate n & 21 & -43 & 15 & -4.746 \\
R caudate n & 20 & -18 & 27 & -4.405 \\
& & & & \\
Irregular > regular & & & & \\
Medial frontal & & & & \\
L ant cingulate g & -9 & 11 & 32 & 3.846 \\
R SMA & 1 & 5 & 49 & 5.203 \\
R ant cingulate g & 7 & 13 & 42 & 4.291 \\
R ant cingulate g & 3 & 20 & 36 & 4.159 \\
Lateral frontal & & & & \\
L precentral g & -41 & -4 & 43 & 3.913 \\
L precentral s & -42 & 3 & 27 & 5.125 \\
L precentral s & -50 & 7 & 21 & 4.714 \\
L precentral s & -51 & 0 & 36 & 4.127 \\
L pars opercularis & -47 & 12 & 3 & 4.467 \\
L pars triangularis & -52 & 24 & 10 & 3.884 \\
L pars triangularis & -42 & 20 & 7 & 3.648 \\
L inf frontal s & -49 & 32 & 17 & 4.498 \\
L inf frontal s & -36 & 14 & 22 & 3.931 \\
R precentral s & 43 & 7 & 27 & 4.345 \\
R precentral s & 51 & 5 & 42 & 3.472 \\
R pars opercularis & 44 & 21 & 19 & 4.582 \\
R pars opercularis & 39 & 22 & 8 & 4.570 \\
R pars opercularis & 43 & 13 & 0 & 4.042 \\
R mid frontal g & 49 & 23 & 28 & 3.548 \\
Anterior insula & & & & \\
L ant insula & 32 & 22 & -1 & 4.297 \\
L ant insula & -28 & 18 & 3 & 4.117 \\
L ant insula & -30 & 10 & 11 & 3.665 \\
R ant insula & 29 & 12 & 0 & 4.809 \\
Superior parietal & & & & \\
L IPS & -24 & -70 & 34 & 4.865 \\
L IPS & -39 & -56 & 45 & 4.374 \\
L dorsal SMG & -50 & -43 & 40 & 4.133 \\
L IPS & -34 & -48 & 33 & 4.074 \\
L SPL & -28 & -64 & 53 & 3.771 \\
Brainstem & & & & \\
L midbrain & -6 & -21 & -4 & 4.043 \\
R midbrain & & & -20 & 4.142 \\
Pons & & & 4.206
\end{tabular}

Regular > irregular

None

Regular $>$ nonword Angular gyrus/MTG

$\mathrm{L}$ angular $\mathrm{g}$

$\mathrm{L}$ angular $\mathrm{g} / \mathrm{MTG}$

$\mathrm{L}$ angular $\mathrm{g} / \mathrm{MTG}$

$$
\begin{array}{r}
-4 \\
-4 \\
-4 \\
-47 \\
-4 \\
4 \\
4 \\
5 \\
48
\end{array}
$$

$\mathrm{L}$ angular $\mathrm{g}$

$\mathrm{L}$ angular $\mathrm{g}$

$\mathrm{R}$ angular $\mathrm{g}$

$\mathrm{R}$ angular $\mathrm{g}$

$\mathrm{R}$ angular $\mathrm{g}$

R MTG 48

Dorsal prefrontal

\begin{tabular}{lrrrr} 
L sup frontal s & -24 & 24 & 42 & 4.823 \\
L middle frontal g & -36 & 13 & 42 & 4.788 \\
R sup frontal s & 24 & 21 & 43 & 4.116 \\
\hline
\end{tabular}

5.064

4.611

4.451

4.265

3.646

5.549

5.186

4.902

4.114
Appendix A (continued)

\begin{tabular}{lrrrr}
\hline Location & \multicolumn{1}{c}{$y$} & \multicolumn{1}{c}{$z$} & $Z$ scor \\
\hline Regular $>$ nonword & & & & \\
Ventromedial frontal & & & & \\
L vent cingulate g & -8 & 24 & -1 & 4.680 \\
L vent cingulate g & -3 & 21 & -10 & 4.468 \\
L vent cingulate g & -13 & 46 & -1 & 3.977 \\
L vent cingulate g & -12 & 45 & 9 & 3.51 \\
L vent cingulate g & -8 & 35 & 6 & 3.35 \\
R vent cingulate g & 4 & 34 & 1 & 4.12 \\
R vent cingulate g & 8 & 14 & -8 & 3.690 \\
Ventromedial temporal & & & & \\
L collateral s & -31 & -35 & -10 & 4.65 \\
L parahippocampus & -21 & -33 & -12 & 4.269 \\
Posterior medial & & & & \\
L post cingulate g & -12 & -55 & 14 & 5.437 \\
L precuneus & -5 & -58 & 37 & 4.129 \\
L post cingulate g & -16 & -51 & 30 & 3.685 \\
L cuneus & -9 & -97 & 9 & 4.419 \\
L cuneus & -8 & -97 & 24 & 3.817 \\
L cuneus & -2 & -71 & 20 & 3.514 \\
R post cingulate g & 1 & -57 & 21 & 4.374 \\
R post cingulate g & 6 & -38 & 36 & 4.262 \\
R post cingulate g & 12 & -51 & 12 & 4.068 \\
R precuneus & 4 & -49 & 36 & 3.676 \\
R cuneus & 14 & -96 & 19 & 4.695 \\
\end{tabular}

Nonword $>$ regular

Medial frontal

$\mathrm{L}$ ant cingulate $\mathrm{g}$

R SMA

$\mathrm{R}$ ant cingulate $\mathrm{g}$

Lateral frontal

$\mathrm{L}$ precentral $\mathrm{g}$

L precentral $g$

L FEF

$\mathrm{L}$ precentral s

L pars opercularis

$\mathrm{L}$ pars triangularis

$\mathrm{L}$ inf frontal s

$\mathrm{L}$ inf frontal $\mathrm{s}$

$\mathrm{R}$ central s

$\mathrm{R}$ central s

$\mathrm{R}$ precentral $\mathrm{s}$

R FEF

$\mathrm{R}$ precentral $\mathrm{s}$

$\mathrm{R}$ pars opercularis

$\mathrm{R}$ pars triangularis

$\mathrm{R}$ inf frontal $\mathrm{s}$

$\mathrm{R}$ mid frontal $\mathrm{g}$

$\mathrm{R}$ mid frontal $\mathrm{g}$

Anterior insula

$\mathrm{L}$ ant insula

$\mathrm{L}$ ant insula

$\mathrm{R}$ ant insula

Superior parietal
L IPS
L IPS
L dorsal SMG
L dorsal SMG
$\mathrm{R}$ dorsal SMG
R IPS
R IPS

R IPS \begin{tabular}{l}
-4.424 \\
-6.305 \\
-5.631 \\
-5.268 \\
-4.291 \\
-5.085 \\
-5.882 \\
-4.571 \\
-4.274 \\
-5.707 \\
-4.044 \\
-4.701 \\
-3.758 \\
-3.557 \\
-5.214 \\
-4.981 \\
-5.106 \\
-4.395 \\
-4.529 \\
-4.442 \\
-3.352 \\
-6.243 \\
-4.593 \\
-5.488 \\
-6.290 \\
-5.396 \\
-4.804 \\
-4.548 \\
-5.752 \\
-5.459 \\
-5.102 \\
-4.875 \\
\hline
\end{tabular}
680

3.977

3.511

690

654

5.437

4.419

3.514

4.374

4.262
4.068

3.676

4.695 
Appendix A (continued)

\begin{tabular}{|c|c|c|c|c|}
\hline Location & $x$ & $y$ & $z$ & $Z$ score \\
\hline \multicolumn{5}{|l|}{ Nonword > regular } \\
\hline \multicolumn{5}{|l|}{ Superior parietal } \\
\hline R IPS & 29 & -52 & 35 & -4.447 \\
\hline R SPL & 11 & -66 & 58 & -4.4 \\
\hline R IPS & 23 & -84 & 31 & -4.2 \\
\hline R SPL & 21 & -62 & 56 & $-3.9^{\prime}$ \\
\hline R SPL & 42 & -52 & 54 & -3.79 \\
\hline \multicolumn{5}{|l|}{ Lateral occipital } \\
\hline $\mathrm{L}$ inf occipital $\mathrm{g}$ & -26 & -92 & -7 & -4.9 \\
\hline L mid occipital $g$ & -29 & -86 & 8 & -4.5 \\
\hline L mid occipital $g$ & -27 & -80 & 18 & -4.3 \\
\hline L sup occipital $g$ & -15 & -79 & 34 & -4.0 \\
\hline L inf occipital $g$ & -40 & -73 & -6 & -3.8 \\
\hline $\mathrm{R}$ mid occipital $\mathrm{g}$ & 39 & -86 & 1 & -4.3 \\
\hline $\mathrm{R}$ mid occipital $\mathrm{g}$ & 31 & -83 & 17 & -3.4 \\
\hline \multicolumn{5}{|l|}{ Posterior temporal } \\
\hline $\mathrm{L}$ inf temporal $\mathrm{s}$ & -49 & -63 & -11 & -4.4 \\
\hline $\mathrm{L}$ fusiform $\mathrm{g}$ & -41 & -51 & -20 & -3.9 \\
\hline \multicolumn{5}{|l|}{ Superior temporal } \\
\hline $\mathrm{R}$ sup temporal $\mathrm{g}$ & 62 & 1 & -4 & -3.3 \\
\hline \multicolumn{5}{|l|}{ Subcortical } \\
\hline $\mathrm{L}$ thalamus & -9 & -17 & 5 & -4.0 \\
\hline $\mathrm{R}$ thalamus & 6 & -14 & -1 & -3.9 \\
\hline $\mathrm{R}$ thalamus & 9 & -16 & 12 & -3.508 \\
\hline \multicolumn{5}{|l|}{ Brainstem } \\
\hline $\mathrm{L}$ midbrain & -7 & -19 & -5 & -4.5 \\
\hline Midbrain & -1 & -24 & -14 & -3.691 \\
\hline
\end{tabular}

Irregular $>$ nonword Angular gyrus

$\begin{array}{lrrrr}\text { L angular g } & -43 & -69 & 33 & 5.853 \\ \text { L angular g } & -47 & -66 & 14 & 4.690 \\ \text { L mid occipital g } & -49 & -86 & 19 & 3.809 \\ \text { R angular g } & 44 & -67 & 33 & 4.659 \\ \text { R angular g } & 44 & -53 & 23 & 4.217 \\ \text { Dorsal prefrontal } & & & & \\ \text { L sup frontal s } & -16 & 24 & 49 & 4.987 \\ \text { L sup frontal g } & -13 & 28 & 39 & 4.276 \\ \text { L mid frontal g } & -38 & 10 & 45 & 3.990 \\ \text { L mid frontal g } & -26 & 16 & 47 & 3.665 \\ \text { Lateral prefrontal } & & & & \\ \text { L pars orbitalis } & -39 & 25 & -9 & 4.076 \\ \text { Ventromedial frontal } & & & & \\ \text { L vent cingulate g } & -9 & 26 & -2 & 4.912 \\ \text { L vent cingulate g } & -13 & 40 & 2 & 4.052 \\ \text { Ventromedial temporal } & & & & \\ \text { L parahippocampus } & -20 & -32 & -12 & 5.008 \\ \text { L collateral s } & -30 & -33 & -13 & 4.786 \\ \text { Posterior medial } & & & & \\ \text { L post cingulate g } & -11 & -52 & 16 & 4.702 \\ \text { L post cingulate g } & -7 & -49 & 28 & 3.481\end{array}$

Nonword $>$ irregular

Medial frontal

\begin{tabular}{lrrrr} 
L SMA & -7 & -2 & 55 & -4.401 \\
R SMA & 4 & 2 & 55 & -4.761 \\
Lateral frontal & & & & \\
L FEF & -27 & -11 & 46 & -4.921 \\
L precentral g & -48 & -12 & 44 & -4.301 \\
L precentral g & -40 & -12 & 25 & -3.582 \\
L precentral s & -48 & 0 & 28 & -4.234 \\
L precentral s & -51 & 2 & 13 & -4.150 \\
Superior parietal & & & & \\
L dorsal SMG & -36 & -39 & 33 & -5.390 \\
\hline
\end{tabular}

Appendix A (continued)

\begin{tabular}{lllll}
\hline Location & $x$ & $y$ & $z$ & $Z$ score \\
\hline $\begin{array}{l}\text { Nonword > irregular } \\
\text { Superior parietal }\end{array}$ & & & & \\
$\quad$ L IPS & -22 & -69 & 42 & -5.054 \\
L IPS & -33 & -51 & 39 & -4.448 \\
L SPL & -16 & -71 & 56 & -3.722 \\
L IPS/dorsal SMG & -48 & -42 & 45 & -3.390 \\
R IPS & 32 & -56 & 43 & -5.438 \\
R IPS & 36 & -46 & 40 & -5.339 \\
R IPS & 22 & -66 & 46 & -4.898 \\
R SPL & 28 & -66 & 57 & -4.880 \\
R IPS & 25 & -67 & 31 & -3.617 \\
R dorsal SMG & 35 & -40 & 30 & -3.315 \\
Lateral occipital & & & & \\
$\quad$ L inf occipital g & -23 & -94 & -5 & -4.059 \\
L inf occipital g & -35 & -85 & -7 & -3.678 \\
Posterior temporal & & & & \\
$\quad$ L inf temporal s & -44 & -58 & -5 & -4.487
\end{tabular}

Positive imageability correlations

Angular gyrus

$\mathrm{L}$ angular $\mathrm{g}$

$\mathrm{L}$ angular $\mathrm{g}$

$\mathrm{R}$ angular $\mathrm{g}$

$\mathrm{R}$ angular $\mathrm{g}$

$\mathrm{R}$ angular $\mathrm{g} / \mathrm{SMG}$

$\mathrm{R}$ angular $\mathrm{g}$

$\mathrm{R}$ angular $\mathrm{g}$

$\mathrm{R}$ angular $\mathrm{g}$

$\mathrm{R}$ angular $\mathrm{g}$

$\mathrm{R}$ angular $\mathrm{g}$

Middle temporal gyrus

$\mathrm{R}$ mid temporal $\mathrm{g}$

$\mathrm{R}$ mid temporal $\mathrm{g}$

$\mathrm{R}$ mid temporal $\mathrm{g}$

$\mathrm{R}$ mid temporal $\mathrm{g}$

$\mathrm{R}$ mid temporal $\mathrm{g}$

$\mathrm{R}$ mid temporal $\mathrm{g}$

Dorsal prefrontal

L sup frontal $\mathrm{s}$

$\mathrm{L}$ mid frontal $\mathrm{g}$

$\mathrm{L}$ mid frontal $\mathrm{g}$

$\mathrm{R}$ mid frontal $\mathrm{g}$

$\mathrm{R}$ mid frontal $\mathrm{g}$

$\mathrm{R}$ mid frontal $\mathrm{g}$

$\mathrm{R}$ sup frontal $\mathrm{s}$

$\mathrm{R}$ sup frontal $\mathrm{s}$

-57
-48

$-54$

$-58$

31

4.617

3.846

3.388

5.409

5.204

4.908

4.454

4.400

4.169

3.830

3.354

4.431

4.409

4.061

3.972

3.905

3.814

$\mathrm{R}$ sup frontal $\mathrm{s}$

$\mathrm{R}$ sup frontal $\mathrm{g}$

$\mathrm{R}$ sup frontal $\mathrm{s}$

$\mathrm{R}$ sup frontal $\mathrm{s}$

$\mathrm{R}$ sup frontal $\mathrm{g}$

Ventromedial temporal

L collateral s

Posterior medial

$\mathrm{L}$ post cingulate $\mathrm{g}$

$\mathrm{L}$ post cingulate $\mathrm{g}$

$\mathrm{L}$ precuneus

$\mathrm{L}$ post cingulate $\mathrm{g}$

$\mathrm{L}$ precuneus

$\mathrm{R}$ post cingulate $\mathrm{g}$

$\mathrm{R}$ post cingulate $\mathrm{g}$ 
Appendix A (continued)

\begin{tabular}{lrrrr}
\hline Location & $x$ & $y$ & $z$ & $Z$ score \\
\hline Negative imageability correlations & & & \\
Medial frontal & & & & \\
L ant cingulate g & -10 & 8 & 42 & -5.359 \\
L SMA & -5 & 2 & 52 & -4.744 \\
L ant cingulate g & -9 & 24 & 29 & -3.781 \\
R ant cingulate g & 8 & 12 & 42 & -4.212 \\
Lateral frontal & & & & \\
L precentral s & -41 & -2 & 27 & -5.450 \\
L precentral g & -47 & -5 & 41 & -4.043 \\
L pars opercularis & -53 & 10 & 20 & -4.234 \\
L pars opercularis & -46 & 17 & -2 & -4.095 \\
L pars triangularis & -46 & 25 & 13 & -4.520 \\
L inf frontal s & -42 & 10 & 22 & -4.349 \\
Anterior insula & & & & \\
L ant insula & -35 & 26 & 12 & -3.774 \\
\hline
\end{tabular}

\section{References}

Adler, C.M., Sax, K.W., Holland, S.K., Schmithorst, V., Rosenberg, L., Strakowski, S.M., 2001. Changes in neuronal activation with increasing attention demand in healthy volunteers: an fMRI study. Synapse 42, $266-272$.

Andreasen, N.C., O’Leary, D.S., Cizadlo, T., et al., 1995. Remembering the past: two facets of episodic memory explored with positron emission tomography. Am. J. Psychiatry 152, 1576-1585.

Andrews, S., 1989. Frequency and neighborhood effects on lexical access: activation or search? J. Exp. Psychol., Learn. Mem. Cogn. 5, $802-814$.

Andrews, S., Scarratt, D.R., 1998. Rule and analogy mechanisms in reading nonwords: hough dou peapel rede gnew wirds? J. Exp. Psychol. Hum. Percept. Perform. 24, 1052-1086.

Antrobus, J.S., Singer, J.L., Greenberg, S., 1966. Studies in the stream of consciousness: experimental enhancement and suppression of spontaneous cognitive processes. Percept. Mot. Skills 23, 399-417.

Baayen, H., Schreuder, R., 1999. War and peace: morphemes and full forms in a noninteractive activation parallel dual-route model. Brain Lang. 68, $27-32$.

Baayen, R.H., Piepenbrock, R., Gulikers, L., 1995. The CELEX lexical database (CD-ROM), 2.5 Edition Linguistic Data Consortium, University of Pennsylvania, Philadelphia.

Badgaiyan, R.D., Posner, M.I., 1998. Mapping the cingulate cortex in response selection and monitoring. NeuroImage 7, 255-260.

Balota, D.A., Cortese, M.J., Sergent-Marshall, S.D., Spieler, D.H., Yap, M.J., 2004. Visual word recognition of single-syllable words. J. Exp. Psychol. Gen. 133, 283-316.

Barde, L.H.F., Thompson-Schill, S.L., 2002. Models of functional organization of lateral prefrontal cortex in verbal working memory: evidence in favor of the process model. J. Cogn. Neurosci. 14, $1054-1063$

Beauchamp, M.S., Cox, R.W., DeYoe, E.A., 1997. Graded effects of spatial and featural attention on human area MT and associated motion processing areas. J. Neurophysiol. 78, 516-520.

Binder, J.R., Price, C.J., 2001. Functional imaging of language. In: Cabeza, R., Kingstone, A. (Eds.), Handbook of Functional Neuroimaging of Cognition. MIT Press, Cambridge, MA, pp. 187-251.

Binder, J.R., Frost, J.A., Hammeke, T.A., Bellgowan, P.S.F., Rao, S.M., Cox, R.W., 1999. Conceptual processing during the conscious resting state: a functional MRI study. J. Cogn. Neurosci. $11,80-93$

Binder, J.R., McKiernan, K.A., Parsons, M., et al., 2003. Neural correlates of lexical access during visual word recognition. J. Cogn. Neurosci. 15, $372-393$.
Binder, J.R., Liebenthal, E., Possing, E.T., Medler, D.A., Ward, B.D., 2004. Neural correlates of sensory and decision processes in auditory object identification. Nature Neurosci. 7, 295-301.

Binder, J.R., Westbury, C.F., Possing, E.T., McKiernan, K.A., Medler, D.A. in press. Distinct brain systems for processing concrete and abstract concepts. J. Cogn. Neurosci.

Bird, H., Franklin, S., Howard, D., 2001. Age of acquisition and imageability ratings for a large set of words, including verbs and function words. Behav. Res. Meth. Instr. Comput. 33, 73-79.

Botvinick, M., Nystrom, L.E., Fissel, K., Carter, C.S., Cohen, J.D., 1999. Conflict monitoring versus selection-for-action in anterior cingulate cortex. Nature 402, 179-181.

Braver, T.S., Cohen, J.D., Nystrom, L.E., Jonides, J., Smith, E.E., Noll, D.C., 1997. A parametric study of prefrontal cortex involvement in human working memory. NeuroImage 5, 49-62.

Braver, T.S., Barch, D.M., Gray, J.R., Molfese, D.L., Snyder, A., 2001. Anterior cingulate cortex and response conflict: effects of frequency, inhibition and errors. Cereb. Cortex 11, 825-836.

Carr, T.H., Pollatsek, A., 1985. Recognizing printed words: a look at current models. In: Besner, D., Waller, T.G., MacKinnon, G.E. (Eds.), Reading Research: Advances in Theory and Practice. Academic Press, London, pp. 2-82.

Carreiras, M., Perea, M., Grainger, J., 1997. Effects of orthographic neighborhood in visual word recognition: cross-task comparison. J. Exp. Psychol., Learn. Mem. Cogn. 23, 857-871.

Carter, C.S., Braver, T.S., Barch, D.M., Botvinick, M.M., Noll, D., Cohen, J.D., 1998. Anterior cingulate cortex, error detection, and the online monitoring of performance. Science 280, 747-749.

Chawla, D., Phillips, J., Büchel, C., Edwards, R., Friston, K.J., 1998. Speed-dependent motion-sensitive responses in V5: an fMRI study. NeuroImage 7, 86-96.

Cohen, J.D., MacWhinney, B., Flatt, M.R., Provost, J., 1993. PsyScope: a new graphic interactive environment for designing psychology experiments. Behav. Res. Meth. Instr. Comput. 25, 257-271.

Cohen, L., Lehéricy, S., Chochon, F., Lemer, C., Rivaud, S., Dehaene, S., 2002. Language-specific tuning of visual cortex? Functional properties of the Visual Word Form Area. Brain 125, $1054-1069$.

Coltheart, M., Davelaar, E., Jonasson, J.T., Besner, D., 1977. Access to the internal lexicon. In: Dornic, S. (Ed.), Attention and Performance VI. Academic Press, New York, pp. 535-555.

Coltheart, M., Besner, D., Jonasson, J.T., Davelaar, E., 1979. Phonological encoding in the lexical decision task. Q. J. Exp. Psychol. 31, 489-507.

Coltheart, M., Curtis, B., Atkins, P., Haller, M., 1993. Models of reading aloud: dual-route and parallel-distributed-processing approaches. Psychol. Rev. 100, 589-608.

Coltheart, M., Rastle, K., Perry, C., Langdon, R., Ziegler, J., 2001. DRC: a dual route cascaded model of visual word recognition and reading aloud. Psychol. Rev. 108, 204-256.

Corbetta, M., Shulman, G.L., 2002. Control of goal-directed and stimulus-driven attention in the brain. Nature Rev. Neurosci. 3, 201-215.

Cortese, M.J., Fugett, A., 2004. Imageability ratings for 3,000 monosyllabic words. Behav. Res. Meth. Instr. Comput. 36, 384-387.

Cox, R.W., 1996. AFNI: software for analysis and visualization of functional magnetic resonance NeuroImages. Comput. Biomed. Res. $29,162-173$

Dale, A.M., Fischl, B., Sereno, M.I., 1999. Cortical surface-based analysis: I. Segmentation and surface reconstruction. NeuroImage 9, $179-194$.

Damasio, H., Tranel, D., Grabowski, T., Adolphs, R., Damasio, A., 2004. Neural systems behind word and concept retrieval. Cognition 92, $179-229$

Démonet, J.-F., Chollet, F., Ramsay, S., et al., 1992. The anatomy of phonological and semantic processing in normal subjects. Brain 115, $1753-1768$. 
D’Esposito, M., Postle, B.R., Ballard, D., Lease, J., 1999. Maintenance versus manipulation of information held in working memory: an eventrelated fMRI study. Brain Cogn. 41, 66-86.

Fiez, J.A., Balota, D.A., Raichle, M.E., Petersen, S.E., 1999. Effects of lexicality, frequency, and spelling-to-sound consistency on the functional anatomy of reading. Neuron 24, 205-218.

Forster, K.I., Shen, D., 1996. No enemies in the neighborhood: absence of inhibitory neighborhood effects in lexical decision and semantic categorization. J. Exp. Psychol., Learn. Mem. Cogn. 22, $696-713$.

Gainotti, G., 2000. What the locus of brain lesion tells us about the nature of the cognitive defect underlying category-specific disorders: a review. Cortex 36, 539-559.

Gitelman, D.R., Nobre, A.C., Parrish, T.B., et al., 1999. A large-scale distributed network for covert spatial attention: further anatomical delineation based on stringent behavioural and cognitive controls. Brain 122, $1093-1106$.

Grainger, J., Jacobs, A.M., 1996. Orthographic processing in visual word recognition: a multiple read-out model. Psychol. Rev. 103, 518-565.

Hagoort, P., Indefrey, P., Brown, C., Herzog, H., Steinmetz, H., Seitz, R.J., 1999. The neural circuitry involved in the reading of German words and pseudowords: a PET study. J. Cogn. Neurosci. 11, 383-398.

Harm, M.W., Seidenberg, M.S., 2004. Computing the meanings of words in reading: cooperative division of labor between visual and phonological processes. Psychol. Rev. 111, 662-720.

Herbster, A.N., Mintun, M.A., Nebes, R.D., Becker, J.T., 1997. Regional cerebral blood flow during word and nonword reading. Hum. Brain Mapp. 5, 84-92.

Honey, G.D., Bullmore, E.T., Sharma, T., 2000. Prolonged reaction time to a verbal working memory task predicts increased power of posterior parietal cortical activation. NeuroImage 12, 495-503.

Horovitz, S.G., Skudlarski, P., Gore, J.C., 2002. Correlations and dissociations between BOLD signal and p300 amplitude in an auditory oddball task: a parametric approach to combining fMRI and ERP. Magn. Reson. Imaging 20, 319-325.

Howard, D., Patterson, K., Wise, R., et al., 1992. The cortical localization of the lexicons. Brain 115, 1769-1782.

Huntsman, L.A., Lima, S.D., 1996. Orthographic neighborhood structure and lexical access. J. Psycholinguist. Res. 25, 417-429.

Ischebeck, A., Indefrey, P., Usui, N., Nose, I., Hellwig, F., Taira, M., 2004. Reading in a regular orthography: an fMRI study investigating the role of visual familiarity. J. Cogn. Neurosci. 16, 727-741.

James, W., 1890. Principles of Psychology. Dover Publications, New York.

Jobard, G., Crivello, F., Tzourio-Mazoyer, N., 2003. Evaluation of the dual route theory of reading: a metanalysis of 35 neuroimaging studies. NeuroImage 20, 693-712.

Jonides, J., Schumacher, E.H., Smith, E.E., et al., 1997. The task-load of verbal working memory affects regional brain activation as measured by PET. J. Cogn. Neurosci. 9, 462-475.

Jonides, J., Schumacher, E., Smith, E., et al., 1998. The role of the parietal cortex in verbal working memory. J. Neurosci. 18, 5026-5034.

Joubert, S.A., Lecours, A.R., 2000. The role of sublexical graphemic processing in reading. Brain Lang. 72, 1-13.

Kastner, S., Ungerleider, L.G., 2000. Mechanisms of visual attention in the human cortex. Annu. Rev. Neurosci. 23, 315-341.

Krawczyk, D.C., 2002. Contributions of the prefrontal cortex to the neural basis of human decision making. Neurosci. Biobehav. Rev. 26, $631-664$.

LaBar, K.S., Gitelman, D.R., Parrish, T.B., Mesulam, M.M., 1999. Neuroanatomic overlap of working memory and spatial attention networks: a functional MRI comparison within subjects. NeuroImage $10,695-704$.

Marshall, J.C., Newcombe, F., 1973. Patterns of paralexia: a psycholinguistic approach. J. Psycholinguist. Res. 2, 175-199.

Martin, A., 2001. Functional imaging of semantic memory. In: Cabeza, R., Kingstone, A. (Eds.), Handbook of Functional Neuroimaging of Cognition. MIT Press, Cambridge, MA, pp. 153-186.
Mazoyer, B., Zago, L., Mellet, E., et al., 2001. Cortical networks for working memory and executive functions sustain the conscious resting state in man. Brain Res. Bull. 54, 287-298.

McCandliss, B.D., Cohen, L., Dehaene, S., 2003. The visual word form area: expertise for reading in the fusiform gyrus. Trends Cogn. Neurosci. 7, 293-299.

McGuire, P.K., Paulesu, E., Frackowiak, R.S.J., Frith, C.D., 1996. Brain activity during stimulus independent thought. NeuroReport 7, 2095-2099.

McKague, M., Pratt, C., Johnston, M.B., 2001. The effect of oral vocabulary on reading visually novel words: a comparison of the dual-route-cascaded and triangle frameworks. Cognition 80, 239-270.

McKiernan, K.A., Kaufman, J.N., Kucera-Thompson, J., Binder, J.R., 2003. A parametric manipulation of factors affecting task-induced deactivation in functional neuroimaging. J. Cogn. Neurosci. 15, 394-408.

Mechelli, A., Gorno-Tempini, M.L., Price, C.J., 2003. Neuroimaging studies of word and pseudoword reading: consistencies, inconsistencies, and limitations. J. Cogn. Neurosci. 15, 260-271.

Menon, V., Adleman, N.E., White, C.D., Glover, G.H., Reiss, A.L., 2001. Error-related brain activation during a Go/NoGo response inhibition task. Hum. Brain Mapp. 12, 131-143.

Mesulam, M.M., 1999. Spatial attention and neglect: parietal, frontal and cingulate contributions to the mental representation and attentional targeting of salient extrapersonal events. Philos. Trans. R. Soc. Lond., B 354, $1325-1346$.

Meyer, D.E., Schvaneveldt, R.W., Ruddy, M.G., 1974. Functions of graphemic and phonemic codes in visual word recognition. Mem. Cognit. 2, 309-321.

Morton, J., Patterson, K., 1980. A new attempt at an interpretation, or, an attempt at a new interpretation. In: Coltheart, M., Patterson, K., Marshall, J.C. (Eds.), Deep Dyslexia. Routledge and Kegan Paul, London, pp. 91-118.

Mummery, C.J., Patterson, K., Hodges, J.R., Price, C.J., 1998. Functional neuroanatomy of the semantic system: divisible by what? J. Cogn. Neurosci. 10, 766-777.

Oldfield, R.C., 1971. The assessment and analysis of handedness: the Edinburgh inventory. Neuropsychologia 9, 97-113.

Paulesu, E., Frith, C.D., Frackowiak, R.S.J., 1993. The neural correlates of the verbal component of working memory. Nature $362,342-345$.

Paulesu, E., McCrory, E., Fazio, F., et al., 2000. A cultural effect on brain function. Nature Neurosci. 3, 91-96.

Perani, D., Dehaene, S., Grassi, F., et al., 1996. Brain processing of native and foreign languages. NeuroReport 7, 2439-2444.

Plaut, D.C., Shallice, T., 1993. Deep dyslexia: a case study of connectionist neuropsychology. Cognit. Neuropsych. 10, 377-500.

Plaut, D.C., McClelland, J.L., Seidenberg, M.S., Patterson, K., 1996. Understanding normal and impaired word reading: computational principles in quasi-regular domains. Psychol. Rev. 103, 45-115.

Poldrack, R.A., Wagner, A.D., Prull, M.W., Desmond, J.E., Glover, G.H., Gabrieli, J.D.E., 1999. Functional specialization for semantic and phonological processing in the left inferior prefrontal cortex. NeuroImage 10, 15-35.

Pope, K.S., Singer, J.L., 1976. Regulation of the stream of consciousness: toward a theory of ongoing thought. In: Schwartz, G.E., Shapiro, D. (Eds.), Consciousness and Self-Regulation. Plenum Press, New York, pp. $101-135$.

Price, C.J., Wise, R.J.S., Warburton, E.A., et al., 1996. Hearing and saying. The functional neuro-anatomy of auditory word processing. Brain 119 , 919-931.

Price, C.J., Moore, C.J., Humphreys, G.W., Wise, R.J.S., 1997. Segregating semantic from phonological processes during reading. J. Cogn. Neurosci. 9, 727-733

Raichle, M.E., McLeod, A.M., Snyder, A.Z., Powers, W.J., Gusnard, D.A., Shulman, G.L., 2001. A default mode of brain function. Proc. Natl. Acad. Sci. 98, 676-682. 
Roskies, A.L., Fiez, J.A., Balota, D.A., Raichle, M.E., Petersen, S.E., 2001. Task-dependent modulation of regions in the left inferior frontal cortex during semantic processing. J. Cogn. Neurosci. 13, 829-843.

Rumsey, J.M., Horwitz, B., Donohue, B.C., Nace, K., Maisog, J.M., Andreason, P., 1997. Phonological and orthographic components of word recognition. A PET-rCBF study. Brain 120, 739-759.

Scott, S.K., Leff, A.P., Wise, R.J.S., 2003. Going beyond the information given: a neural system supporting semantic interpretation. NeuroImage $19,870-876$

Sears, C.R., Hino, Y., Lupker, S.J., 1995. Neighborhood size and neighborhood frequency effects in word recognition. J. Exp. Psychol. Hum. Percept. Perform. 21, 876-900.

Seidenberg, M.S., Waters, G.S., Barnes, M.A., Tanenhaus, M.K., 1984 When does irregular spelling or pronunciation influence word recognition? J. Verbal Learn. Verbal Behav. 23, 383-404.

Seidenberg, M.S., McClelland, J.L., 1989. A distributed, developmental model of word recognition and naming. Psychol. Rev. 96, 523-568

Shulman, G.L., Fiez, J.A., Corbetta, M., et al., 1997. Common blood flow changes across visual tasks: II. Decreases in cerebral cortex. J. Cogn. Neurosci. 9, 648-663.

Simos, P.G., Breier, J.I., Wheless, J.W., et al., 2000. Brain mechanisms for reading: the role of the superior temporal gyrus in word and pseudoword naming. NeuroReport 11, 2443-2447.

Singer, J.L., 1993. Experimental studies of ongoing conscious experience. Experimental and Theoretical Studies of Consciousness. John Wiley and Sons, Chichester, pp. 100-122.

Small, S.L., Noll, D.C., Perfetti, C.A., Hlustik, P., Wellington, R., Schneider, W., 1996. Localizing the lexicon for reading aloud: replication of a PET study using fMRI. NeuroReport 7, 961-965.

Smith, E.E., Jonides, J., Marshuetz, C., Koeppe, R.A., 1998. Components of verbal working memory: evidence from neuroimaging. Proc. Natl. Acad. Sci. 95, 876-882.

Stark, C.E., Squire, L.R., 2001. When zero is not zero: the problem of ambiguous baseline conditions in fMRI. Proc. Natl. Acad. Sci. 98, $12760-12766$
Talairach, J., Tournoux, P., 1988. Co-planar Stereotaxic Atlas of the Human Brain. Thieme Medical Publishers, New York.

Taraban, R., McClelland, J.L., 1987. Conspiracy effects in word recognition. J. Mem. Lang. 26, 608-631.

Teasdale, J.D., Proctor, L., Lloyd, C.A., Baddeley, A.D., 1993. Working memory and stimulus-independent thought: effects of memory load and presentation rate. Eur. J. Cogn. Psychol. 5, 417-433.

Ullsperger, M., von Cramon, D.Y., 2001. Subprocesses of performance monitoring: a dissociation of error processing and response competition revealed by event-related fMRI and ERPs. NeuroImage 14, $1387-1401$

Van Essen, D.C., Drury, H.A., Dickson, J., Harwell, J., Hanlon, D., Anderson, C.H., 2001. An integrated software suite for surface-based analysis of cerebral cortex. J. Am. Med. Inform. Assoc. 8, 443-459.

van Veen, V., Carter, C.S., 2002. The anterior cingulate as a conflict monitor: fMRI and ERP studies. Physiol. Behav. 77, 477-482.

Visser, T.A., Besner, D., 2001. On the dominance of whole-word knowledge in reading aloud. Psychon. Bull. Rev. 8, 560-567.

Wager, T.D., Smith, E.E., 2003. Neuroimaging studies of working memory: a meta-analysis. Cogn. Affect. Behav. Neurosci. 3, 255-274.

Waters, G.S., Seidenberg, M.S., 1985. Spelling-sound effects in reading: time course and decision criteria. Mem. Cognit. 13, 557-572.

Wilson, M.D., 1988. The MRC psycholinguistic database: machine readable dictionary, version 2. Behav. Res. Meth. Instr. Comput. 20, $6-11$

Xu, B., Grafman, J., Gaillard, W.D., et al., 2001. Conjoint and extended neural networks for the computation of speech codes: the neural basis of selective impairment in reading words and pseudowords. Cereb. Cortex 11, 267-277.

Yantis, S., Schwartzbach, J., Serences, J.T., et al., 2002. Transient neural activity in human parietal cortex during spatial attention shifts. Nature Neurosci. 5, 995-1002.

Zeki, S., Watson, J.D.G., Lueck, C.J., Friston, K.J., Kennard, C., Frackowiak, R.S., 1991. A direct demonstration of functional specialisation in human visual cortex. J. Neurosci. 11, 641-649. 